\title{
Synthesis and Characterization of Some New Thiazolidinedione Derivatives Containing a Coumarin Moiety for their Antibacterial and Antifungal Activities
}

\author{
Edris Valadbeigi* and Shahram Ghodsi
}

Department of Chemistry, Faculty of Sciences, Islamic Azad University, Karaj Branch, Karaj, Iran

\begin{abstract}
Simple coumarins and analogues are large class of compounds that have attracted their interest for a long time due to their biological activities. They have shown to be useful as anti-tumoural, anti-HIV agents and as CNS active compounds. Furthermore, they have been reported to have multiple biological activities (anti-coagulant, anti-inflammatory), although all these properties have not been evaluated systematically. In addition, their enzyme inhibition properties, antimicrobial and antioxidant activities are other foremost topics in this field of research. A new series of thiazolidinedione derivatives were synthesized by reacting with coumarin moiety and studied for their antibacterial and antifungal activities. The synthesis of compounds (6a-9c) was achieved through the versatile and efficient synthetic route that involved reaction of thiazolidinedione with appropriately $\alpha$-bromo ketone or $\alpha$-bromo oxime derivatives $(\mathbf{2 a}, \mathbf{5 c})$. The structures of these compounds were established by means of IR, ${ }^{1} \mathrm{H}-\mathrm{NMR},{ }^{13} \mathrm{C}-\mathrm{NMR}$ Mass and elemental analysis.
\end{abstract}

Keywords: Antimicrobial; Chemical synthesis; Coumarin; Thiazolidinedione

\section{Introduction}

The structural and therapeutic diversity of small heterocyclic molecules coupled with their commercial viability has long fascinated organic and medicinal chemists. Heterocycles containing the coumarin ring system include some novel pharmacologically active compounds such as dicumarol, warfarin and novobiocin (Figure 1). Natural coumarins affect the formation and scavenging of ROS and influence free radical-mediated oxidative damage [1]. Azomethine group $(-\mathrm{C}=\mathrm{N}$ )-containing compounds, typically known as Schiff's bases, have been synthesized via condensation of primary amines with active carbonyls. It is well established that the biological activity of hydrazone compounds is associated with the presence of the active $(-\mathrm{CO}-\mathrm{NHN}=\mathrm{C}-)$ pharmacophore and these compounds form a significant category of compounds in medicinal and pharmaceutical chemistry with several biological applications that include antitumoral [2,3], antifungal [49], antibacterial [4-11], antimicrobial [12] and anthelmintic uses [13]. Thiazolidine derivatives are reported to show a variety of biological activities. The presence of a thiazolidine ring in penicillin and related derivatives was the first recognition of its occurrence in nature [14]. Thiazolidine-4-one represents a prevalent scaffold in drug discovery [15]. Literature surveys show that thiazolinylhydrazones exhibit antitubercular and antimicrobial activities [16], and their pronounced antioxidant [17] and antifungal [18] activity has also been reported.

The synthesis of coumarins and their derivatives has attracted considerable attention from organic and medicinal chemists for many years as a large number of natural products contain this heterocyclic nucleus. They are widespread in nature as physiologically active constituents of plants [19-21]. In addition, coumarin derivatives have a broad range of applications in the pharmaceutical, perfume, and cosmetic industries. The diverse biological activities of coumarins is well known as anticoagulants, antithrombotics, antimicrobial, antibacterial activities, anticancer and anti-HIV activity [22-28]. Thus, coumarins containing a Schiff's base and a thiazolidinone moiety are expected to have enhanced biological activities.

\section{Materials and Methods}

\section{Chemistry}

Chemical reagents and all solvents used in this research were bought from Merck AG (Darmstadt, Germany). Melting points were determined in open glass capillaries using Bibby Stuart Scientific $\mathrm{SMP}_{3}$ apparatus (Bibby Sterlin Ltd, U.K.) and are uncorrected. The FT-IR spectra were obtained on a Shimadzu 470 spectrophotometer (potassium bromide disks; Shimadzu, Tokyo, Japan). Mass spectra were also recorded with an Agilent Technologies 5973, Mass Selective Detector (MSD) spectrometer (Wilmigton, USA). ${ }^{1} \mathrm{H}-\mathrm{NMR}$ spectra were recorded using a Bruker 500 spectrometer and ${ }^{13} \mathrm{C}$ - NMR spectra were recorded using a Bruker 300 spectrometer (Bruker Bioscience, Billerica, MA, USA), and chemical shifts are expressed as $\delta(\mathrm{ppm})$ with tetramethylsilane as internal standard. Merck silica gel $60 \mathrm{~F}_{254}$ plates were used for analytical TLC (Merck).

\section{Experimental}

The synthesis of final compounds was obtained via the useful and effective synthetic route indicated in Scheme 1. The starting with 2-hydroxy/ 2-hydroxy-3-methoxy/ 5-boromo-2-hydroxybenzaldehyd and ethylacetoacetate in methanol in the presence of piperidine to give 3-acetyl coumarin, 3-acetyl (5-bromocoumarin) and 3-acetyl (8-methoxy coumarin). Compounds 3-acetyl coumarin, 3-acetyl (5-bromocoumarin) and 3-acetyl (8-methoxy coumarin) were converted to $a$-bromo intermediate by refluxing with $\mathrm{Br}_{2}$ in $\mathrm{CH}_{2} \mathrm{Cl}_{2}$

*Corresponding author: Edris Valadbeigi, Department of Chemistry, Faculty of Sciences, Islamic Azad University, Karaj Branch, Karaj, Iran, Tel: 00989188313734 Fax: 00988346124463; E-mail: edrisvaladbeigi@gmail.com

Received May 26, 2017; Accepted May 27, 2017; Published June 03, 2017

Citation: Valadbeigi E, Ghodsi S (2017) Synthesis and Characterization of Some New Thiazolidinedione Derivatives Containing a Coumarin Moiety for their Antibacterial and Antifungal Activities. Med Chem (Los Angeles) 7: 178-185. doi: 10.4172/2161-0444.1000453

Copyright: (c) 2017 Valadbeigi E, et al. This is an open-access article distributed under the terms of the Creative Commons Attribution License, which permits unrestricted use, distribution, and reproduction in any medium, provided the original author and source are credited. 
<smiles>Cc1oc2ccccc2c(=O)c1Cc1c(C)c2ccccc2oc1=O</smiles>

Dicumarol<smiles>CC(=O)CC(c1ccccc1)c1c(C)c2ccccc2oc1=O</smiles>

Warfarin<smiles>COC1[C@H](C(N)=O)[C@@H](O)[C@@H](Oc2ccc3c(O)c(NC(=O)c4ccc(C)c(CC=C(C)C)c4)c(=O)oc3c2C)OC1(C)C</smiles>

Figure 1: Heterocycles containing the coumarin ring system.

[29]. $\alpha$-bromoketones were converted to $\alpha$-bromo oxioms by stirring with hydroxyl amine hydrochloride, methoxy amine hydrochloride and $O$-benzyl hydroxylamine hydrochloride in methanol at $22-25^{\circ} \mathrm{C}$ $[29,30]$. The final compounds consist of intermediate synthesized reaction with thiazolidinedione in $\mathrm{EtOH}$, in the presence of $\mathrm{KOH}$ at $0^{\circ} \mathrm{C}$ afforded corresponding ketones and oxime derivatives (6a-9c), respectively (Table 1).

2, 4 thiazolidinedione $\left(\mathrm{C}_{3} \mathrm{H}_{3} \mathrm{NO}_{2} \mathrm{~S}\right)$ : In a $250 \mathrm{ml}$ three-necked round-bottomed flask, was placed, solution containing $(56.4 \mathrm{~g} 0.6 \mathrm{~mol})$ of chloracetic acid in $60 \mathrm{ml}$ of water and $(45.6 \mathrm{~g}, 0.6 \mathrm{~mol})$ of thiourea dissolved in $60 \mathrm{ml}$ of water. The mixture was stirred for $15 \mathrm{~min}$. to form a white precipitate, accompanied by considerable cooling. To the contents of the flask was then added slowly $60 \mathrm{ml}$ of concentrated $\mathrm{HCl}$ from a dropping funnel, the flask was then connected with a reflux condenser and gentle heat applied to effect complete solution, after which the reaction mixture was stirred and refluxed for 8-10 h at 100$110^{\circ} \mathrm{C}$. On cooling the contents of the flask solidified to a cluster of white needles (Scheme 2). The product was filtered and washed with water to remove traces of hydrochloric acid and dried. It was purified by recrystallization from ethyl alcohol. Yield: (88\%); M.p: $(122-124)^{\circ} \mathrm{C}$.

3-acetyl-2H-chromen-2-one ( $\left.\mathbf{1 a}, \mathbf{C}_{11} \mathbf{H}_{8} \mathbf{O}_{3}\right):(596 \mathrm{mg}, 3.8 \mathrm{mmol})$ 2-hydroxybenzaldehyd and ethylacetoacetate $(464 \mathrm{mg}, 3.8 \mathrm{mmol})$ in $(14 \mathrm{ml})$ methanol in the presence of piperidine was stirred at $0-4^{\circ} \mathrm{C}$ for $4 \mathrm{~h}$. The precipitated yellow solid was filtered off, washed with cold methanol, and dried to give (1a) (869 mg). Yellow solid; M.p:(188-189) ${ }^{\circ} \mathrm{C}$, yield $=(82 \%)$; IR $\left(\mathrm{KBr}, \mathrm{cm}^{-1}\right)$ : 1734, 1630, 1601, 1572, 1459, 1434, 1363, 1282, 1128, 1094, 1043, 949, 886, 765; ${ }^{1} \mathrm{H}-\mathrm{NMR}(500 \mathrm{MHz}, \mathrm{DMSO}-\mathrm{d} 6)$ : $\delta=2.44\left(\mathrm{~s}, 3 \mathrm{H}, \mathrm{CH}_{3}\right.$ coumarin), $\delta=4.45\left(\mathrm{~s}, 2 \mathrm{H}_{1} \mathrm{CH}_{2}-\mathrm{Br}\right), 7.42(\mathrm{dt}, 1 \mathrm{H}$, H-6 coumarin, J=7.87 and $0.84 \mathrm{~Hz}), 7.51(\mathrm{~d}, 1 \mathrm{H}, \mathrm{H}-8$ coumarin, $\mathrm{J}=6.91$ $\mathrm{Hz}), 7.72(\mathrm{dt}, 1 \mathrm{H}, \mathrm{H}-7$ coumarin, $\mathrm{J}=8.64$ and $1.53 \mathrm{~Hz}), 7.92(\mathrm{dd}, 1 \mathrm{H}$, $\mathrm{H}-5$ coumarin, $\mathrm{J}=7.67$ and $1.39 \mathrm{~Hz}), 8.41(\mathrm{~s}, 1 \mathrm{H}, \mathrm{H}-4$ coumarin) ppm; ${ }^{13} \mathrm{C}-\mathrm{NMR}$ (300 MHz, DMSO-d6): $\delta=32.4,120.3,121.8,127.9,131.8$, $133.2,136.2,140.8,157.5,164.9,198.1 \mathrm{ppm}$; MS $(70 \mathrm{eV}) \mathrm{m} / z:\left[\mathrm{M}^{+}\right], 188$ (100\%); Anal. Calcd for $\mathrm{C}_{11} \mathrm{H}_{8} \mathrm{O}_{3}$ 188.1794, Found 188.1785.

3-acetyl-6-bromo-2H-chromen-2-one (1b, $\left.\mathrm{C}_{11} \mathrm{H}_{7} \mathrm{BrO}_{3}\right)$ : $(585 \mathrm{mg}$, $2.9 \mathrm{mmol}$ ) 5-bromo-2-hydroxybenzaldehyd and ethylacetoacetate (378 $\mathrm{mg}, 2.9 \mathrm{mmol})$ in $(14 \mathrm{ml})$ methanol in the presence of piperidine was
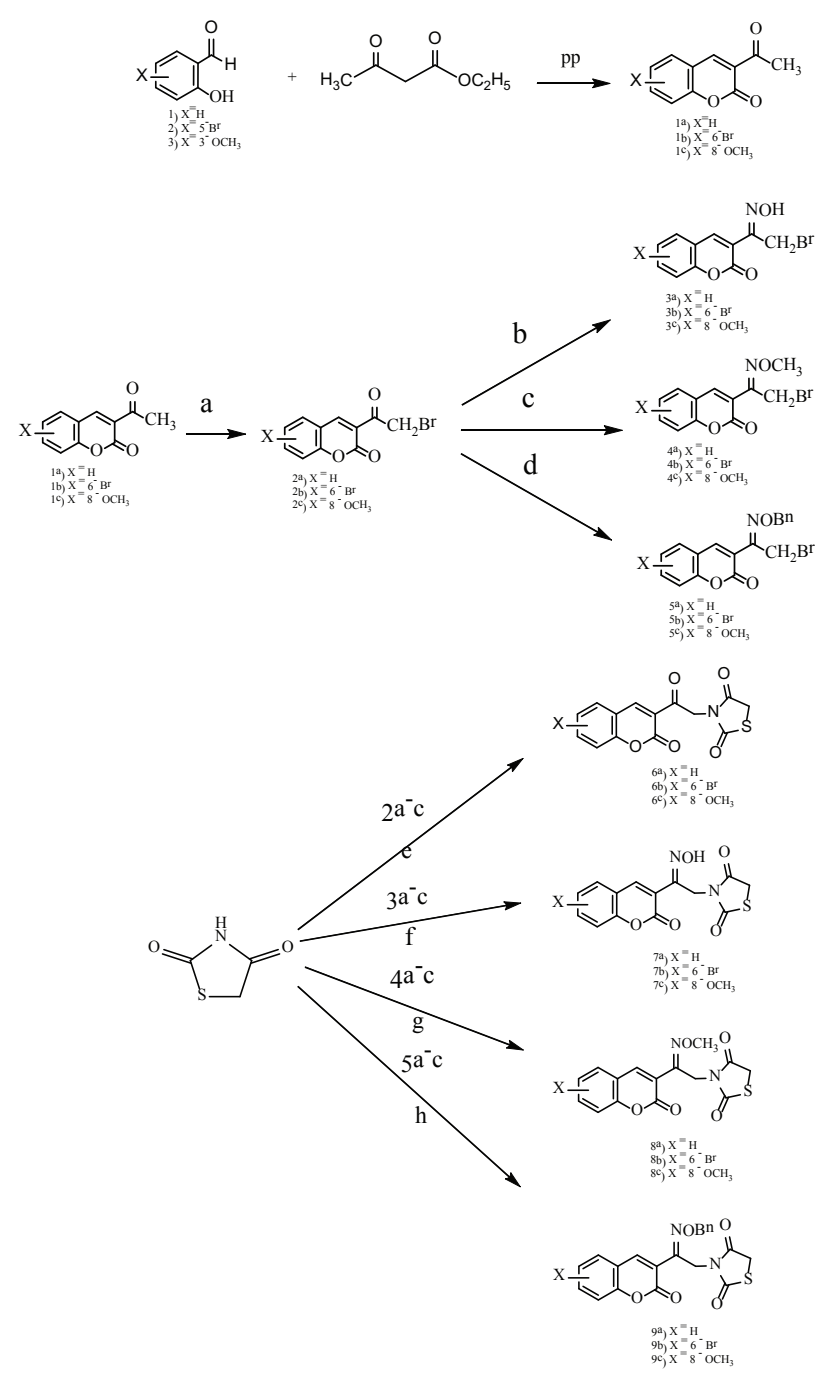

Reagents and conditions: (a) $\mathrm{Br}_{2}, \mathrm{CH}_{2} \mathrm{Cl}_{2}, 22-25^{\circ} \mathrm{C}$, and then reflux; (b) hydroxylamine hydrochloride, $\mathrm{MeOH}^{2}, 22-25^{\circ} \mathrm{C}$; (c) methoxy amine hydrochloride, $\mathrm{MeOH}, 22-25^{\circ} \mathrm{C}$; (d) O-benzyl hydroxylamine hydrochloride, $\mathrm{MeOH}, 22-25^{\circ} \mathrm{C}$; (e), (f), (g), (h) $\mathrm{EtOH}, \mathrm{KOH}, 0^{\circ} \mathrm{C}$.

Scheme 1: Synthesis route of compounds $6 a-9 c$.

stirred at $0-4^{\circ} \mathrm{C}$ for $4 \mathrm{~h}$. The precipitated yellow solid was filtered off, washed with cold methanol, and dried to give (1b) $(809 \mathrm{mg})$. Yellow solid; M.p: $(225-227)^{\circ} \mathrm{C}$, yield $=(84 \%)$; IR $\left(\mathrm{KBr}, \mathrm{cm}^{-1}\right)$ : 1744, 1633, 1610, 1574, 1455, 1437, 1369, 1288, 1131, 1090, 1049, 941, 888, 671; ${ }^{1} \mathrm{H}-\mathrm{NMR}$ (500 MHz, DMSO-d6): $\delta=2.41\left(\mathrm{~s}, 3 \mathrm{H}, \mathrm{CH}_{3}\right.$ coumarin), $\delta=7.20-7.61$ (m, 2H, H-7- H-8 coumarin), $\delta=7.66(\mathrm{~d}, 1 \mathrm{H}, \mathrm{H}-5$ coumarin, J=8.85), $\delta=8.52(\mathrm{~s}, 1 \mathrm{H}, \mathrm{H}-4$ coumarin $) \mathrm{ppm} ;{ }^{13} \mathrm{C}-\mathrm{NMR}(300 \mathrm{MHz}, \mathrm{DMSO}-\mathrm{d} 6)$ : $\delta=31.9,120.5,122.8,126.6,134.2,136.1,139.8,141.4,155.2,164.5$,

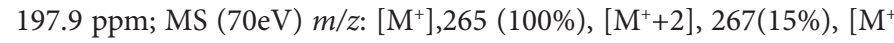
+4], 269 (2\%); Anal. Calcd forC ${ }_{11} \mathrm{H}_{7}{ }^{79} \mathrm{BrO}_{3}$ 267.0755, Found 267.0750.

3-acetyl-8-methoxy-2H-chromen-2-one (1c, $\left.\mathrm{C}_{12} \mathrm{H}_{10} \mathrm{O}_{4}\right):(400 \mathrm{mg}$, $2.6 \mathrm{mmol}$ ) 2-hydroxy-3-methoxybenzaldehyd and ethylacetoacetate $(335 \mathrm{mg}, 2.6 \mathrm{mmol})$ in $(14 \mathrm{ml})$ methanol in the presence of piperidine was stirred at $0-4^{\circ} \mathrm{C}$ for $4 \mathrm{~h}$. The precipitated yellow solid was filtered off, washed with cold methanol, and dried to give (1c) $(605 \mathrm{mg})$. Yellow solid; M.p:(168-169 $)^{\circ} \mathrm{C}$, yield $=(78 \%)$; $\mathrm{IR}\left(\mathrm{KBr}, \mathrm{cm}^{-1}\right): 1738,1641,1616$, $1569,1466,1422,1371,1277,1166,1100,1044,943,890,766 ;{ }^{1} \mathrm{H}-\mathrm{NMR}$ (500 MHz, DMSO-d6): $\delta=2.46$ (s, $3 \mathrm{H}, \mathrm{CH}_{3}$ coumarin), $\delta=4.04(\mathrm{~s}, 3 \mathrm{H}$, 


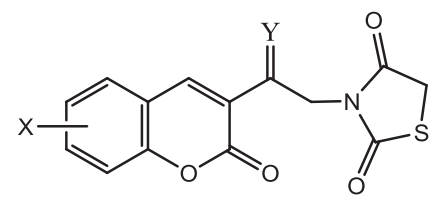

\begin{tabular}{|c|c|c|c|c|c|c|c|}
\hline Compound & $\mathbf{x}$ & $\mathbf{Y}$ & $\mathrm{Mp}\left({ }^{\circ} \mathrm{C}\right)$ & Reaction time (h) & Yield (\%) & Formula & M.W \\
\hline $6 a$ & $\mathrm{H}$ & $\mathrm{O}$ & $161-163$ & 24 & 71 & $\mathrm{C}_{14} \mathrm{H}_{9} \mathrm{NO}_{5} \mathrm{~S}$ & 303.29 \\
\hline $6 b$ & $6-\mathrm{Br}$ & $\mathrm{O}$ & $171-173$ & 24 & 66 & $\mathrm{C}_{14} \mathrm{H}_{8} \mathrm{BrNO}_{5} \mathrm{~S}$ & 382.19 \\
\hline $6 c$ & 8-OMe & $\mathrm{O}$ & $165-167$ & 24 & 68 & $\mathrm{C}_{15} \mathrm{H}_{11} \mathrm{NO}_{6} \mathrm{~S}$ & 333.32 \\
\hline $7 a$ & $\mathrm{H}$ & $\mathrm{NOH}$ & $148-151$ & 24 & 57 & $\mathrm{C}_{14} \mathrm{H}_{10} \mathrm{~N}_{2} \mathrm{O}_{5} \mathrm{~S}$ & 318.30 \\
\hline $7 b$ & $6-\mathrm{Br}$ & $\mathrm{NOH}$ & $177-179$ & 24 & 58 & $\mathrm{C}_{14} \mathrm{H}_{9} \mathrm{BrN}_{2} \mathrm{O}_{5} \mathrm{~S}$ & 397.20 \\
\hline $7 \mathrm{c}$ & 8-OMe & $\mathrm{NOH}$ & 153-155 & 24 & 59 & $\mathrm{C}_{15} \mathrm{H}_{12} \mathrm{~N}_{2} \mathrm{O}_{6} \mathrm{~S}$ & 348.33 \\
\hline $8 a$ & $\mathrm{H}$ & NOMe & $157-159$ & 24 & 58 & $\mathrm{C}_{15} \mathrm{H}_{12} \mathrm{~N}_{2} \mathrm{O}_{5} \mathrm{~S}$ & 332.33 \\
\hline $8 b$ & $6-\mathrm{Br}$ & NOMe & $178-180$ & 24 & 60 & $\mathrm{C}_{15} \mathrm{H}_{11} \mathrm{BrN}_{2} \mathrm{O}_{5} \mathrm{~S}$ & 411.23 \\
\hline $8 c$ & 8-OMe & NOMe & $162-164$ & 24 & 62 & $\mathrm{C}_{16} \mathrm{H}_{14} \mathrm{~N}_{2} \mathrm{O}_{6} \mathrm{~S}$ & 362.06 \\
\hline $9 a$ & $\mathrm{H}$ & NOBn & $183-185$ & 24 & 56 & $\mathrm{C}_{21} \mathrm{H}_{16} \mathrm{~N}_{2} \mathrm{O}_{5} \mathrm{~S}$ & 408.43 \\
\hline $9 b$ & $6-\mathrm{Br}$ & NOBn & $190-192$ & 24 & 55 & $\mathrm{C}_{21} \mathrm{H}_{15} \mathrm{BrN}_{2} \mathrm{O}_{5} \mathrm{~S}$ & 487.32 \\
\hline $9 c$ & 8-OMe & NOBn & $186-188$ & 24 & 54 & $\mathrm{C}_{22} \mathrm{H}_{18} \mathrm{~N}_{2} \mathrm{O}_{6} \mathrm{~S}$ & 438.45 \\
\hline
\end{tabular}

Table 1: Structures and physicochemical data of compounds $6 a-9 \mathrm{c}$<smiles>NC(=S)N1CC(=O)NC1=O</smiles>

Scheme 2: Synthesis of 2, 4-thiazolidinedione

O- $\mathrm{CH}_{3}$ coumarin), 7.39 (dt, $1 \mathrm{H}, \mathrm{H}-6$ coumarin, $\mathrm{J}=7.85$ and $0.81 \mathrm{~Hz}$ ), $7.79(\mathrm{dt}, 1 \mathrm{H}, \mathrm{H}-7$ coumarin, $\mathrm{J}=8.70$ and $1.53 \mathrm{~Hz}), 7.95$ (dd, $1 \mathrm{H}, \mathrm{H}-5$ coumarin, J=7.68 and $1.40 \mathrm{~Hz}), 8.48(\mathrm{~s}, 1 \mathrm{H}, \mathrm{H}-4$ coumarin) ppm; ${ }^{13} \mathrm{C}-\mathrm{NMR}(300 \mathrm{MHz}, \mathrm{DMSO}-\mathrm{d} 6): \delta=32.1,57.4,122.1,124.2,127.7$, $132.6,134.6,140.9,144.5,152.4,164.5,198.1 \mathrm{ppm}$; MS $(70 \mathrm{eV}) \mathrm{m} / \mathrm{z}$ : $\left[\mathrm{M}^{+}\right], 218$ (100\%); Anal. Calcd for $\mathrm{C}_{12} \mathrm{H}_{10} \mathrm{O}_{4}$ 218.2054, Found 218.2056.

3-(2-bromoacetyl)-2H-chromen-2-one $\left(2 \mathrm{a}, \mathrm{C}_{11} \mathrm{H}_{7} \mathrm{BrO}_{3}\right)$ : To a solution of (1a) $(500 \mathrm{mg}, 2.7 \mathrm{mmol})$ was added $\mathrm{Br}_{2}(430 \mathrm{mg}, 2.7 \mathrm{mmol})$ in dichloromethane a dropwise. The completion of the reaction was monitored by TLC. The precipitated yellow solid was filtered off, washed with cold methanol, and dried to give (2a) $(680 \mathrm{mg})$. Yellow crystal; M.p: $(148-150)^{\circ} \mathrm{C}$, yield $=(82 \%)$; IR $\left(\mathrm{KBr}, \mathrm{cm}^{-1}\right): 1733,1630,1600,1562,1452$, $1434,1366,1277,1163,1094,1043,1001,886,765 ;{ }^{1} \mathrm{H}-\mathrm{NMR}(500 \mathrm{MHz}$, DMSO-d6): $\delta=4.57$ (s, 2H,CH $-\mathrm{Br}), \delta=7.33-7.76(\mathrm{~m}, 3 \mathrm{H}, \mathrm{H}-6$ and $\mathrm{H}-7$ and $\mathrm{H}-8$ coumarin), $\delta=7.84$ (d, $1 \mathrm{H}, \mathrm{H}-5$ coumarin, $\mathrm{J}=8.70 \mathrm{~Hz}$ ), $\delta=8.48$ (s, $1 \mathrm{H}, \mathrm{H}-4$ coumarin) ppm; ${ }^{13} \mathrm{C}-\mathrm{NMR}(300 \mathrm{MHz}, \mathrm{DMSO}-\mathrm{d} 6): \delta=35.8$, 120.8, 121.9, 128.7, 131.5, 134.8, 136.2, 139.8, 156.2, 166.6, 197.7 ppm; MS $(70 \mathrm{eV}) \mathrm{m} / z:\left[\mathrm{M}^{+}\right], 265(100 \%),\left[\mathrm{M}^{+}+2\right], 267(20 \%),\left[\mathrm{M}^{+}+4\right], 269$ (1.6\%); Anal. Calcd for $\mathrm{C}_{11} \mathrm{H}_{7}^{79} \mathrm{BrO}_{3} 267.0755$, Found 267.0752.

6-bromo-3-(2-bromoacetyl)-2H-chromen-2-one (2b, $\left.\mathrm{C}_{11} \mathrm{H}_{6} \mathrm{Br}_{2} \mathrm{O}_{3}\right)$ : To a solution of $(\mathbf{1 b})(500 \mathrm{mg}, 1.8 \mathrm{mmol})$ was added $\mathrm{Br}_{2}(287 \mathrm{mg}, 1.8 \mathrm{mmol})$ in dichloromethane a dropwise. The completion of the reaction was monitored by TLC. The precipitated yellow solid was filtered off, washed with cold methanol, and dried to give (2b) (685 mg). Yellow crystal; M.p: $(235-237)^{\circ} \mathrm{C}$, yield $=(87 \%)$; IR $\left(\mathrm{KBr}, \mathrm{cm}^{-1}\right): 1731,1636,1596,1571$, 1449, 1429, 1371, 1276, 1158, 1105, 1050, 1011, 880,669; ${ }^{1} \mathrm{H}-\mathrm{NMR}(500$ MHz, DMSO-d6) : $\delta=4.47$ (s, 2H, $\left.\mathrm{CH}_{2}-\mathrm{Br}\right), \delta=7.42-7.52(\mathrm{~m}, 2 \mathrm{H}, \mathrm{H}-7$ and $\mathrm{H}-8$ coumarin), $\delta=7.60$ (d, $1 \mathrm{H}, \mathrm{H}-5$ coumarin, $\mathrm{J}=8.81), \delta=8.48(\mathrm{~s}$, $1 \mathrm{H}, \mathrm{H}-4$ coumarin) ppm; ${ }^{13} \mathrm{C}-\mathrm{NMR}(300 \mathrm{MHz}, \mathrm{DMSO}-\mathrm{d} 6): \delta=35.9$,
120.7, 121.6, 126.3, 133.8, 135.7, 136.8, 140.9, 154.8, 164.8, $198.1 \mathrm{ppm}$; MS (70eV) $m / z:\left[\mathrm{M}^{+}\right], 345(100 \%),\left[\mathrm{M}^{+}+2\right], 347(25 \%),\left[\mathrm{M}^{+}+4\right], 349$ (2\%); Anal. Calcd for $\mathrm{C}_{11} \mathrm{H}_{6}^{79} \mathrm{Br}_{2} \mathrm{O}_{3} 345.9715$, Found 345.9710.

3-(2-bromoacetyl)-8-methoxy-2H-chromen-2-one (2c, $\left.\mathrm{C}_{12} \mathrm{H}_{9} \mathrm{BrO}_{4}\right)$ : To a solution of (1c) (500 mg, $2.3 \mathrm{mmol}$ ) was added $\mathrm{Br}_{2}$ (366 mg, 2.3 $\mathrm{mmol}$ ) in dichloromethane a dropwise. The completion of the reaction was monitored by TLC. The precipitated yellow solid was filtered off, washed with cold methanol, and dried to give $(2 \mathrm{c})(702 \mathrm{mg})$. Yellow crystal; M.p: $(178-179)^{\circ} \mathrm{C}$, yield $=(81 \%)$; IR $\left(\mathrm{KBr}, \mathrm{cm}^{-1}\right): 1720,1644$, 1612, 1555, 1460, 1444, 1370, 1282, 1166, 1099, 1047, 1012, 890, 673; ${ }^{1} \mathrm{H}-\mathrm{NMR}$ (500 MHz, DMSO-d6): $\delta=4.08$ (s, $3 \mathrm{H}, \mathrm{O}-\mathrm{CH}_{3}$ coumarin), $\delta=4.51\left(\mathrm{~s}, 2 \mathrm{H}, \mathrm{CH}_{2}-\mathrm{Br}\right), \delta=7.18-7.71(\mathrm{~m}, 2 \mathrm{H}, \mathrm{H}-6$ and $\mathrm{H}-7$ coumarin), $\delta=7.75(\mathrm{~d}, 1 \mathrm{H}, \mathrm{H}-5$ coumarin, $\mathrm{J}=8.66 \mathrm{~Hz}), \delta=8.47(\mathrm{~s}, 1 \mathrm{H}, \mathrm{H}-4$ coumarin $)$ ppm; ${ }^{13} \mathrm{C}-\mathrm{NMR}$ (300 MHz, DMSO-d6): $\delta=36.5,57.3,121.5,122.7$, $128.3,131.8,135.1,142.4,145.6,152.5,162.6,198.7$ ppm; MS (70eV)

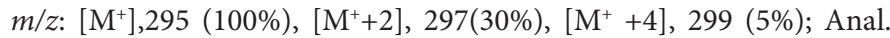
Calcd for $\mathrm{C}_{12} \mathrm{H}_{9}^{79} \mathrm{BrO}_{4}$ 297.1015, Found 297.1006.

3-(2-bromo-1-(hydroxyimino)ethyl)-2H-chromen-2-one (3a, $\left.\mathbf{C}_{11} \mathbf{H}_{8} \mathbf{B r N O}_{3}\right)$ : A solution of (2a) $(267 \mathrm{mg}, 1.0 \mathrm{mmol})$ and hydroxylamine hydrochloride $(209 \mathrm{mg}, 3.0 \mathrm{mmol})$ in methanol $(10 \mathrm{ml})$ was stirred at $22-25^{\circ} \mathrm{C}$ for $24 \mathrm{~h}$. Then, water $(25 \mathrm{ml})$ was added and the precipitate was filtered and washed with water to give compound (3a) (376 mg). White powder; M.p: $(185-187)^{\circ} \mathrm{C}$, yield $=(79 \%)$; IR $(\mathrm{KBr}, \mathrm{cm}$ $\left.{ }^{1}\right): 1737,1674,1609,1566,1449,1440,1360,1280,1166,1101,1046$, 1010, 888, 761; ${ }^{1} \mathrm{H}-\mathrm{NMR}(500 \mathrm{MHz}, \mathrm{DMSO}-\mathrm{d} 6): \delta=4.42\left(\mathrm{~s}, 2 \mathrm{H}, \mathrm{CH}_{2}-\right.$ $\mathrm{Br}), 7.46(\mathrm{dt}, 1 \mathrm{H}, \mathrm{H}-6$ coumarin, $\mathrm{J}=7.87$ and $0.84 \mathrm{~Hz}), 7.51(\mathrm{~d}, 1 \mathrm{H}, \mathrm{H}-8$ coumarin, $\mathrm{J}=6.91 \mathrm{~Hz}), 7.72(\mathrm{dt}, 1 \mathrm{H}, \mathrm{H}-7$ coumarin, $\mathrm{J}=8.64$ and 1.53 $\mathrm{Hz}$ ), 7.90 (dd, $1 \mathrm{H}, \mathrm{H}-5$ coumarin, J=7.67 and $1.39 \mathrm{~Hz}$ ), $8.28(\mathrm{~s}, 1 \mathrm{H}, \mathrm{H}-4$ coumarin), 12.41 (s, $1 \mathrm{H}$,oxime) ppm; ${ }^{13} \mathrm{C}-\mathrm{NMR}$ (300 MHz, DMSO-d6): 
Citation: Valadbeigi E, Ghodsi S (2017) Synthesis and Characterization of Some New Thiazolidinedione Derivatives Containing a Coumarin Moiety for their Antibacterial and Antifungal Activities. Med Chem (Los Angeles) 7: 178-185. doi: 10.4172/2161-0444.1000453

$\delta=35.7,120.9,123.3,127.6,130.2,134.8,136.4,140.9,155.5,163.8,198.3$

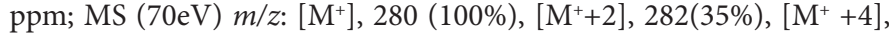
284 (10\%); Anal. Calcd for $\mathrm{C}_{11} \mathrm{H}_{8}{ }^{79} \mathrm{BrNO}_{3} 282.0901$, Found 282.0905.

6-bromo-3-(2-bromo-1-(hydroxyimino)ethyl)-2H-chromen-2one (3b, $\left.\mathrm{C}_{11} \mathrm{H}_{7} \mathrm{Br}_{2} \mathrm{NO}_{3}\right)$ : A solution of $(2 \mathrm{~b})(346 \mathrm{mg}, 1.0 \mathrm{mmol})$ and hydroxylamine hydrochloride $(209 \mathrm{mg}, 3.0 \mathrm{mmol})$ in methanol $(10 \mathrm{ml})$ was stirred at $22-25^{\circ} \mathrm{C}$ for $24 \mathrm{~h}$. Then, water $(25 \mathrm{ml})$ was added and the precipitate was filtered and washed with water to give compound $(\mathbf{3 b})$ (259 mg). White powder; M.p: $(173-175)^{\circ} \mathrm{C}$, yield $=(75 \%)$; IR $(\mathrm{KBr}, \mathrm{cm}$ $\left.{ }^{1}\right): 1728,1635,1609,1560,1459,1430,1360,1279,1174,1092,1048$, 994, 892, 670; ${ }^{1} \mathrm{H}-\mathrm{NMR}(500 \mathrm{MHz}, \mathrm{DMSO}-\mathrm{d} 6): \delta=4.22\left(\mathrm{~s}, 2 \mathrm{H}^{-\mathrm{CH}_{2}}\right.$ $\mathrm{Br}), \delta=7.20-7.57(\mathrm{~m}, 2 \mathrm{H}, \mathrm{H}-7$ and $\mathrm{H}-8$ coumarin), $\delta=7.64(\mathrm{~d}, 1 \mathrm{H}$, $\mathrm{H}-5$ coumarin, $\mathrm{J}=8.78), \delta=8.22(\mathrm{~s}, 1 \mathrm{H}, \mathrm{H}-4$ coumarin), $\delta=12.48(\mathrm{~s}, 1 \mathrm{H}$, oxime) ppm; ${ }^{13} \mathrm{C}-\mathrm{NMR}(300 \mathrm{MHz}, \mathrm{DMSO}-\mathrm{d} 6): \delta=36.8,121.1,123.9$, 126.4, 134.5, 136.2, 137.7, 139.8, 155.6, 164.6, 198.9 ppm; MS (70eV) $m / z:\left[\mathrm{M}^{+}\right], 360(100 \%),\left[\mathrm{M}^{+}+2\right], 362(15 \%),\left[\mathrm{M}^{+}+4\right], 364$ (2\%); Anal. Calcd for $\mathrm{C}_{11} \mathrm{H}_{7}^{79} \mathrm{Br}_{2} \mathrm{NO}_{3} 360.9862$, Found 360.9855 .

3-(2-bromo-1-(hydroxyimino)ethyl)-8-methoxy-2H-chromen2-one (3c, $\left.\mathrm{C}_{12} \mathrm{H}_{10} \mathrm{BrNO}_{4}\right)$ : A solution of $(2 \mathrm{c})(297 \mathrm{mg}, 1.0 \mathrm{mmol})$ and hydroxylamine hydrochloride $(209 \mathrm{mg}, 3.0 \mathrm{mmol})$ in methanol $(10 \mathrm{ml})$ was stirred at $22-25^{\circ} \mathrm{C}$ for $24 \mathrm{~h}$. Then, water $(25 \mathrm{ml})$ was added and the precipitate was filtered and washed with water to give compound (3c) $(389 \mathrm{mg})$. White powder; M.p: $(165-167)^{\circ} \mathrm{C}$, yield $=(77 \%)$; IR $(\mathrm{KBr}$, $\left.\mathrm{cm}^{-1}\right): 1730,1723,1677,1615,1444,1361,1258,1171,1025,955,835$, 760; ${ }^{1} \mathrm{H}-\mathrm{NMR}$ (500 MHz, DMSOd6): $\delta=4.06$ (s, 3H,O- $\mathrm{CH}_{3}$ coumarin), $\delta=4.41\left(\mathrm{~s}, 2 \mathrm{H}, \mathrm{CH}_{2}-\mathrm{Br}\right), 7.51(\mathrm{dt}, 1 \mathrm{H}, \mathrm{H}-6$ coumarin, $\mathrm{J}=7.91$ and 0.88 $\mathrm{Hz}$ ), 7.72 (dt, $1 \mathrm{H}, \mathrm{H}-7$ coumarin, $J=8.68$ and $1.56 \mathrm{~Hz}$ ), 7.93 (dd, $1 \mathrm{H}, \mathrm{H}-5$ coumarin, J=7.71 and $1.38 \mathrm{~Hz}$ ), 8.33 (s, $1 \mathrm{H}, \mathrm{H}-4$ coumarin), 12.39 (s, $1 \mathrm{H}$,oxime) ppm; ${ }^{13} \mathrm{C}-\mathrm{NMR}$ (300 MHz, DMSO-d6): $\delta=36.1,57.6,121.1$, $123.9,126.4,130.5,134.7,141.1,145.5,152.6,163.6,197.8$ ppm; MS $(70 \mathrm{eV}) \mathrm{m} / z:\left[\mathrm{M}^{+}\right], 310(100 \%),\left[\mathrm{M}^{+}+2\right], 312(20 \%),\left[\mathrm{M}^{+}+4\right], 314(1.6 \%) ;$ Anal. Calcd for $\mathrm{C}_{12} \mathrm{H}_{10}{ }^{79} \mathrm{BrNO}_{4} 312.1161$, Found 312.1164.

3-(2-bromo-1-(methoxyimino)ethyl)-2H-chromen-2-one (4a, $\left.\mathrm{C}_{12} \mathrm{H}_{10} \mathrm{BrNO}_{3}\right)$ : To a stirred solution of (2a) $(267 \mathrm{mg}, 1.0 \mathrm{mmol})$ in $\mathrm{MeOH}(16 \mathrm{ml})$ at $22-25^{\circ} \mathrm{C}$, was added $25 \%$ solution of $O$-methyl hydroxyl ammonium chloride in diluted $\mathrm{HCl}(1002 \mathrm{mg}, 3.0 \mathrm{mmol})$. After $24 \mathrm{~h}$ stirring at $22-25^{\circ} \mathrm{C}$, the precipitated white solid was filtered off, washed with cold methanol, and dried to give (4a) $(977 \mathrm{mg})$. White powder; M.p: $(151-153)^{\circ} \mathrm{C}$, yield $=(77 \%)$; IR $\left(\mathrm{KBr}, \mathrm{cm}^{-1}\right)$ : 1729,1669 , $1611,1558,1455,1429,1365,1284,1111,1099,1041,995,894,769$; ${ }^{1} \mathrm{H}-\mathrm{NMR}$ (500 MHz, DMSO-d6): $\delta 4.12$ (s, 3H, O-CH3oxime), 4.51 (s, $\left.2 \mathrm{H}, \mathrm{CH}_{2}-\mathrm{Br}\right), 7.38(\mathrm{t}, 1 \mathrm{H}, \mathrm{H}-6$ coumarin, J=7.39 Hz), $7.48(\mathrm{~d}, 1 \mathrm{H}$, $\mathrm{H}-8$ coumarin, $\mathrm{J}=8.67 \mathrm{~Hz}), 7.62-7.89(\mathrm{~m}, 2 \mathrm{H}, \mathrm{H}-5$ and $\mathrm{H}-7$ coumarin), 8.15(s, 1H, H-4 coumarin) ppm; ${ }^{13} \mathrm{C}-\mathrm{NMR}$ (300 MHz, DMSO-d6): $\delta=35.4,64.8,120.6,123.8,128.3,131.9,134.2,136.1,143.1,157.1,165.4$, $198.1 \mathrm{ppm}$; MS $(70 \mathrm{eV}) \mathrm{m} / \mathrm{z}:\left[\mathrm{M}^{+}\right], 294(100 \%),\left[\mathrm{M}^{+}+2\right], 296(35 \%)$, $\left[\mathrm{M}^{+}+4\right], 298$ (10\%); Anal. Calcd for $\mathrm{C}_{12} \mathrm{H}_{10}{ }^{79} \mathrm{BrNO}_{3} 296.1167$, Found 296.1163 .

6-bromo-3-(2-bromo-1-(methoxyimino)ethyl)-2H-chromen2-one (4b, $\left.\mathrm{C}_{12} \mathrm{H}_{9} \mathrm{Br}_{2} \mathrm{NO}_{3}\right)$ : To a stirred solution of (2b) (346 mg, 1.0 $\mathrm{mmol})$ in $\mathrm{MeOH}(16 \mathrm{ml})$ at $22-25^{\circ} \mathrm{C}$, was added $25 \%$ solution of $\mathrm{O}$-methyl hydroxyl ammonium chloride in diluted $\mathrm{HCl}(1002 \mathrm{mg}, 3.0$ $\mathrm{mmol}$ ). After $24 \mathrm{~h}$ stirring at $22-25^{\circ} \mathrm{C}$, the precipitated white solid was filtered off, washed with cold methanol, and dried to give (4b) $(996 \mathrm{mg})$. M.p: $(158-160)^{\circ} \mathrm{C}$, yield $=(74 \%)$; $\operatorname{IR}\left(\mathrm{KBr}, \mathrm{cm}^{-1}\right): 1731,1641,1612,1570$, 1447, 1439, 1364, 1276, 1156, 1088, 1056, 1014, 896, 663; ${ }^{1} \mathrm{H}-\mathrm{NMR}(500$ $\mathrm{MHz}, \mathrm{DMSO}-\mathrm{d} 6): \delta=4.11$ (s, 3H, O- $\mathrm{CH}_{3}$ oxime), $\delta=4.24\left(\mathrm{~s}, 2 \mathrm{H}_{1} \mathrm{CH}_{2}-\right.$ $\mathrm{Br}$ ), $\delta=7.01-7.50$ ( $\mathrm{m}, 2 \mathrm{H}, \mathrm{H}-7$ and $\mathrm{H}-8$ coumarin), $\delta=8.33$ (d, $1 \mathrm{H}, \mathrm{H}-5$ coumarin,J=8.75), $\delta=8.29$ (s, $1 \mathrm{H}, \mathrm{H}-4$ coumarin) ppm; ${ }^{13} \mathrm{C}-\mathrm{NMR}(300$
MHz, DMSO-d6): $\delta=36.4,64.8,119.9$ 122.6, 127.6, 130.6, 132.6, 136.1,

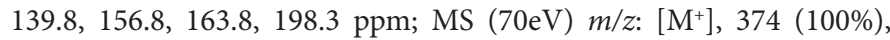
$\left[\mathrm{M}^{+}+2\right], 376(18 \%),\left[\mathrm{M}^{+}+4\right], 378(2.5 \%)$; Anal. Calcd for $\mathrm{C}_{12} \mathrm{H}_{9}{ }^{79} \mathrm{Br}_{2} \mathrm{NO}_{3}$ 375.0128 , Found 375.0118 .

3-(2-bromo-1-(methoxyimino)ethyl)-8-methoxy-2H-chromen2-one (4c, $\left.\mathrm{C}_{13} \mathrm{H}_{12} \mathrm{BrNO}_{4}\right)$ : To a stirred solution of (2c) $(297 \mathrm{mg}$, $1.0 \mathrm{mmol})$ in $\mathrm{MeOH}(16 \mathrm{ml})$ at $22-25^{\circ} \mathrm{C}$, was added $25 \%$ solution of $O$-methyl hydroxyl ammonium chloride in diluted $\mathrm{HCl}(1002 \mathrm{mg}, 3.0$ $\mathrm{mmol}$ ). After $24 \mathrm{~h}$ stirring at $22-25^{\circ} \mathrm{C}$, the precipitated white solid was filtered off, washed with cold methanol, and dried to give (4c)(987 mg). White powder; M.p: $(141-143)^{\circ} \mathrm{C}$, yield $=(76 \%)$; IR $\left(\mathrm{KBr}, \mathrm{cm}^{-1}\right): 1726$, 1636, 1601, 1576, 1461, 1429, 1368, 1251, 1123, 1097, 1053, 1014, 891, $761 ;{ }^{1} \mathrm{H}-\mathrm{NMR}(500 \mathrm{MHz}, \mathrm{DMSO}-\mathrm{d} 6): \delta=4.06\left(\mathrm{~s}, 3 \mathrm{H}, \mathrm{O}-\mathrm{CH}_{3}\right.$ coumarin), $\delta=4.25\left(\mathrm{~s}, 2 \mathrm{H}, \mathrm{CH}_{2}-\mathrm{Br}\right), \delta=4.15\left(\mathrm{~s}, 3 \mathrm{H}, \mathrm{O}-\mathrm{CH}_{3}\right.$ oxime $), 7.41(\mathrm{t}, 1 \mathrm{H}, \mathrm{H}-6$ coumarin, $\mathrm{J}=7.42 \mathrm{~Hz}$ ), 7.62-7.89 (m, $2 \mathrm{H}, \mathrm{H}-5$ and $\mathrm{H}-7$ coumarin), 8.18(s, 1H, H-4 coumarin) ppm; ${ }^{13} \mathrm{C}-\mathrm{NMR}$ (300 MHz, DMSO-d6): $\delta=36.3,57.4,65.5,121.8,122.7,127.8,131.7,134.9,141.7,144.8$, $152.4,164.8,198.1 \mathrm{ppm}$; MS $(70 \mathrm{eV}) \mathrm{m} / z:\left[\mathrm{M}^{+}\right], 324(100 \%),\left[\mathrm{M}^{+}+2\right]$, 326(25\%), $\left[\mathrm{M}^{+}+4\right]$, 328 (2\%); Anal. Calcd for $\mathrm{C}_{13} \mathrm{H}_{12}{ }^{79} \mathrm{BrNO}_{4} 326.1427$, Found 326.1421 .

3-(1-(benzyloxyimino)-2-bromoethyl)-2H-chromen-2-one (5a, $\left.\mathrm{C}_{18} \mathrm{H}_{14} \mathrm{BrNO}_{3}\right)$ : A solution of (2a) $(267 \mathrm{mg}, 1.0 \mathrm{mmol})$ and O-benzyl hydroxylaminehydrochloride ( $479 \mathrm{mg}, 3.0 \mathrm{mmol})$ in methanol $(16 \mathrm{~mL})$ was stirred at $22-25^{\circ} \mathrm{C}$ overnight. The resulting suspension wascooled $0-4^{\circ} \mathrm{C}$ and the precipitated white solid was filtered off, washed with cold methanol, and dried to give (5a) $(552 \mathrm{mg})$. White powder; M.p: $(101-103)^{\circ} \mathrm{C}$, yield $=(74 \%) ; \mathrm{IR}\left(\mathrm{KBr}, \mathrm{cm}^{-1}\right): 1711,1617,1600,1459,1370$, 1241, 1172, 1101, 1061, 891, 755, 741; 1H-NMR (500 MHz, DMSO-d6) 4.47 (s, 2H, $\left.\mathrm{CH}_{2}-\mathrm{Br}\right), 5.29$ (s, 2H, O-CH $\left.-\mathrm{Ph}\right), 7.10-7.55$ (m, 7H, H-6 coumarin, H-8 coumarin and phenyl), 7.61-7.86 (m, 2H, H-5 and H-7 coumarin), 8.01 (s, $1 \mathrm{H}, \mathrm{H}-4$ coumarin) ppm; ${ }^{13} \mathrm{C}-\mathrm{NMR}(300 \mathrm{MHz}$, DMSO-d6): $\delta=36.6,80.4,122.8,122.3,126.1,128.2,129.8(2 \mathrm{C}), 130.2$, $131.9(2 \mathrm{C}), 133.1,134.6,138.9,143.4,155.1,163.2,184.1 \mathrm{ppm} ; \mathrm{MS}$ $(70 \mathrm{eV}) \mathrm{m} / \mathrm{z}:\left[\mathrm{M}^{+}\right], 371(100 \%),\left[\mathrm{M}^{+}+2\right], 373(15 \%),\left[\mathrm{M}^{+}+4\right], 375(2 \%)$; Anal. Calcd for $\mathrm{C}_{18} \mathrm{H}_{14}{ }^{79} \mathrm{BrNO}_{3} 372.2127$, Found 372.2121.

3-(1-(benzyloxyimino)-2-bromoethyl)-6-bromo-2H-chromen2-one (5b, $\mathrm{C}_{18} \mathrm{H}_{13} \mathrm{Br}_{2} \mathrm{NO}_{3}$ ): A solution of (2b) (346 g, $1.0 \mathrm{mmol}$ ) and O-benzyl hydroxyl amine hydrochloride $(0.479 \mathrm{~g}, 3.0 \mathrm{mmol})$ in methanol $(16 \mathrm{ml})$ was stirred at $22-25^{\circ} \mathrm{C}$ overnight. The resulting suspension was cooled $0-4^{\circ} \mathrm{C}$ and the precipitated white solid was filtered off, washed with cold methanol, and dried to give $544 \mathrm{mg}$ (5b). White powder; M.p: $(105-107)^{\circ} \mathrm{C}$, yield $=(66 \%)$; IR $\left(\mathrm{KBr}, \mathrm{cm}^{-1}\right): 1719$, $1625,1616,1456,1369,1245,1171,1105,1049,888,776,733 ;{ }^{1} \mathrm{H}-\mathrm{NMR}$ (500 MHz, DMSO-d6): $\delta=4.51$ (s, $2 \mathrm{H}, \mathrm{CH}_{2}-\mathrm{Br}$ ), $\delta=5.39$ (s, $2 \mathrm{H}, \mathrm{O}_{-} \mathrm{CH}_{2}-$ $\mathrm{Ph}), \delta=7.35-7.57$ (m, 7H, H7,H8coumarin and phenyl), $\delta=7.71(\mathrm{~d}, 1 \mathrm{H}$, $\mathrm{H} 5$ coumarin, $\mathrm{J}=8.71$ ), $\delta=8.11$ (s, $1 \mathrm{H}, \mathrm{H}-4$ coumarin) $\mathrm{ppm} ;{ }^{13} \mathrm{C}-\mathrm{NMR}$ (300 MHz, DMSO-d6): $\delta=36.9,79.1,122.2,128.4,129.7(2 \mathrm{C}), 130.8$, 132.3(2C), 134.2, 135.8, 137.2, 141.5, 146.3, 153.8, 165.1, 171.9, 183.8

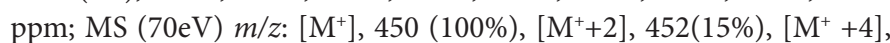
454 (2\%); Anal. Calcd for $\mathrm{C}_{18} \mathrm{H}_{13}{ }^{79} \mathrm{Br}_{2} \mathrm{NO}_{3}$ 451.1087, Found 451.1081.

3-(1-(benzyloxyimino)-2-bromoethyl)-8-methoxy-2Hchromen-2-one (5c, $\left.\mathrm{C}_{19} \mathrm{H}_{16} \mathrm{BrNO}_{4}\right)$ : A solution of (2c) $(297 \mathrm{mg}, 1.0$ $\mathrm{mmol}$ ) and O-benzyl hydroxyl amine hydrochloride (0.479 g, 3.0 $\mathrm{mmol})$ in methanol $(16 \mathrm{ml})$ was stirred at $22-25^{\circ} \mathrm{C}$ overnight. The resulting suspension was cooled $0-4^{\circ} \mathrm{C}$ and the precipitated white solid was filtered off, washed with cold methanol, and dried to give $527 \mathrm{mg}$ (5c). White powder; M.p: $(105-107)^{\circ} \mathrm{C}$, yield $=(68 \%)$; IR $\left(\mathrm{KBr}, \mathrm{cm}^{-1}\right)$ : $1715,1621,1607,1450,1362,1239,1165,1094,1051,881,765$ 
Citation: Valadbeigi E, Ghodsi S (2017) Synthesis and Characterization of Some New Thiazolidinedione Derivatives Containing a Coumarin Moiety for their Antibacterial and Antifungal Activities. Med Chem (Los Angeles) 7: 178-185. doi: 10.4172/2161-0444.1000453

$734^{1} \mathrm{H}-\mathrm{NMR}(500 \mathrm{MHz}, \mathrm{DMSO}-\mathrm{d} 6): \delta=3.76$ (s, 3H, O- $\mathrm{CH}_{3}$ coumarin), $\delta=4.44\left(\mathrm{~s}, 2 \mathrm{H}, \mathrm{CH}_{2}-\mathrm{Br}\right), \delta=5.36\left(\mathrm{~s}, 2 \mathrm{H}, \mathrm{O}-\mathrm{CH}_{2}-\mathrm{Ph}\right), \delta=7.35-7.55(\mathrm{~m}, 7 \mathrm{H}$, $\mathrm{H}-6, \mathrm{H} 7$, coumarin and phenyl), $\delta=7.81(\mathrm{~d}, 1 \mathrm{H}, \mathrm{H} 5$-coumarin. $\mathrm{J}=7.72)$, $\delta=8.00\left(\mathrm{~s}, 1 \mathrm{H}, \mathrm{H}-4\right.$ coumarin) ppm; ${ }^{13} \mathrm{C}-\mathrm{NMR}(300 \mathrm{MHz}, \mathrm{DMSO}-\mathrm{d} 6)$ : $\delta=37.2,57.8,79.9122 .5,125.7,127.6,128.7(2 \mathrm{C}), 130.9,133.5(2 \mathrm{C})$, $134.8,136.4,138.9,145.1,153.2,163.4,172.8,183.1 \mathrm{ppm}$; MS $(70 \mathrm{eV})$ $m / z:\left[\mathrm{M}^{+}\right], 401(100 \%),\left[\mathrm{M}^{+}+2\right], 403(18 \%),\left[\mathrm{M}^{+}+4\right], 405$ (2.5\%); Anal. Calcd for $\mathrm{C}_{19} \mathrm{H}_{16}{ }^{79} \mathrm{BrNO}_{4} 402.2386$, Found 402.2379.

\section{General procedure for the synthesis of compounds 6a-9c}

A mixture of (2a-c) or oxime derivatives $(\mathbf{3 a}-\mathbf{5 c})(0.5 \mathrm{mmol})$, thiazolidinedione $(0.5 \mathrm{mmol})$, and $\mathrm{KOH}(0.5 \mathrm{mmol})$ in $\mathrm{EtOH}(10 \mathrm{ml})$, was stirred at $0^{\circ} \mathrm{C}$ for $24 \mathrm{~h}$. After consumption of thiazolidinedione, water $(20 \mathrm{ml})$ was added and the precipitate was filtered, washed with water, and recrystallized from methanol-chloroform (9:1) to give compounds (6a-9c).

3-(2-oxo-2-(2-oxo-2H-chromen-3-yl)ethyl)thiazolidine2,4-dione(6a, $\left.\mathrm{C}_{14} \mathrm{H}_{9} \mathrm{NO}_{5} \mathrm{~S}\right)$ : Brown powder; M.p: $(161-163)^{\circ} \mathrm{C}$, yield $=(71 \%)$; IR $\left(\mathrm{KBr}, \mathrm{cm}^{-1}\right): 1758,1609,1589,1494,1459,1375$, 1282, 1279 1104, 756; ${ }^{1} \mathrm{H}-\mathrm{NMR}$ (500 MHz, DMSO-d6): $\delta=4.17$ (s, $2 \mathrm{H}$, $\mathrm{CH}_{2}$-thiazolidinedione $), \delta=5.26\left(\mathrm{~s}, 2 \mathrm{H}, \mathrm{COCH}_{2}\right), \delta=7.44(\mathrm{t}, 1 \mathrm{H}, \mathrm{H}-6$ coumarin, $J=7.76 \mathrm{~Hz}), \delta=7.49(\mathrm{~d}, 1 \mathrm{H}, \mathrm{H}-8$ coumarin, $\mathrm{J}=8.35 \mathrm{~Hz})$, $\delta=7.77(\mathrm{dt}, 1 \mathrm{H}, \mathrm{H}-7$ coumarin, $\mathrm{J}=7.79$ and1.46 Hz), $\delta=7.97(\mathrm{dd}, 1 \mathrm{H}$, $\mathrm{H}-5$ coumarin, $\mathrm{J}=6.59$ and $1.36 \mathrm{~Hz}$ ), $\delta=8.57$ (s, $1 \mathrm{H}, \mathrm{H}-4$ coumarin) ppm; ${ }^{13} \mathrm{C}-\mathrm{NMR}$ (300 MHz, DMSO-d6): $\delta=40.9,60.4,120.5,122.8,128.6$, 131.2, 132.8, 135.6, 140.4, 156.4, 164.6, 171.1, 174.6, 198.7 ppm; MS (70eV) $m / z:\left[\mathrm{M}^{+}\right], 303$ (100\%); Anal. Calcd for $\mathrm{C}_{14} \mathrm{H}_{9} \mathrm{NO}_{5} \mathrm{~S} 303.2900$, Found 303.2894.

3-(2-(6-bromo-2-oxo-2H-chromen-3-yl)-2-oxoethyl) thiazolidine-2,4-dione $\left(6 \mathrm{~b}, \mathrm{C}_{14} \mathrm{H}_{8} \mathrm{BrNO}_{5} \mathrm{~S}\right)$ : Brown powder; M.p: (171$173)^{\circ} \mathrm{C}$, yield $=(66 \%)$; IR $\left(\mathrm{KBr}, \mathrm{cm}^{-1}\right): 1760,1608,1580,1490,1455$, $1379,1291,1284,1119,759 ;{ }^{1} \mathrm{H}-\mathrm{NMR}(500 \mathrm{MHz}, \mathrm{DMSO}-\mathrm{d} 6): \delta=4.18$ (s, $2 \mathrm{H}, \mathrm{CH}_{2}$-thiazolidinedione), $\delta=5.22\left(\mathrm{~s}, 2 \mathrm{H}, \mathrm{COCH}_{2}\right), \delta=7.29-7.52$ ( $\mathrm{m}, 2 \mathrm{H}, \mathrm{H}-7,8$ coumarin), $\delta=7.65(\mathrm{~d}, 1 \mathrm{H}, \mathrm{H}-5$ coumarin $\mathrm{J}=8.80 \mathrm{~Hz})$, $\delta=8.49$ (s, 1H, H-4 coumarin) ppm; ${ }^{13} \mathrm{C}-\mathrm{NMR}(300 \mathrm{MHz}, \mathrm{DMSO}-\mathrm{d} 6)$ : $\delta=40.1,60.3,119.8,122.6,127.3,133.8,135.6,136.8,140.3,155.8$, $163.8,169.5,174.1,198.6 \mathrm{ppm}$; MS $(70 \mathrm{eV}) \mathrm{m} / z:\left[\mathrm{M}^{+}\right], 382(100 \%)$, $\left[\mathrm{M}^{+}+2\right], 384(18 \%),\left[\mathrm{M}^{+}+4\right], 386$ (2.5\%); Anal. Calcd for $\mathrm{C}_{14} \mathrm{H}_{8}{ }^{79} \mathrm{BrNO}_{5} \mathrm{~S}$ 382.1860, Found 382.1852.

3-(2-(8-methoxy-2-oxo-2H-chromen-3-yl)-2-oxoethyl) thiazolidine-2,4-dione $\left(6 \mathrm{c}, \mathrm{C}_{15} \mathrm{H}_{11} \mathrm{NO}_{6} \mathrm{~S}\right)$ : Brown powder; M.p: (165$167)^{\circ} \mathrm{C}$, yield $=(68 \%) ; \operatorname{IR}\left(\mathrm{KBr}, \mathrm{cm}^{-1}\right): 1756,1611,1594,1501,1463,1369$, 1287, 1271, 1111, 767; ${ }^{1} \mathrm{H}-\mathrm{NMR}(500 \mathrm{MHz}, \mathrm{DMSO}-\mathrm{d} 6)$ : $\delta=4.09$ (s, 3H, $\mathrm{O}-\mathrm{CH}_{3}$ coumarin), $\delta=4.17$ (s, $2 \mathrm{H}, \mathrm{CH}_{2}$-thiazolidinedione), $\delta=5.27$ (s, $\left.2 \mathrm{H}, \mathrm{COCH}_{2}\right), \delta=7.27-7.44(\mathrm{~m}, 2 \mathrm{H}, \mathrm{H}-6, \mathrm{H}-7$ coumarin $), \delta=7.90(\mathrm{~d}, 1 \mathrm{H}$, $\mathrm{H}-5$ coumarin, $\mathrm{J}=8.71 \mathrm{~Hz}), 8.44\left(\mathrm{~s}, 1 \mathrm{H}, \mathrm{H}-4\right.$ coumarin) $\mathrm{ppm} ;{ }^{13} \mathrm{C}-\mathrm{NMR}$ (300 MHz, DMSO-d6): $\delta=39.8,58.6,61.3,121.6,123.7,127.3,131.2$, $135.6,140.4,144.4,151.3,163.7,172.8,175.1,198.6$ ppm; MS (70eV) $m / z:\left[\mathrm{M}^{+}\right], 333$ (100\%); Anal. Calcd for $\mathrm{C}_{15} \mathrm{H}_{11} \mathrm{NO}_{6} \mathrm{~S} 333.3159$, Found 333.3154 .

3-(2-(hydroxyimino)-2-(2-oxo-2 H-chromen-3-yl)ethyl) thiazolidine-2,4-dione(7a, $\mathrm{C}_{14} \mathrm{H}_{10} \mathrm{~N}_{2} \mathrm{O}_{5} \mathrm{~S}$ ): Brown powder; M.p: $(148-151)^{\circ} \mathrm{C}$, yield $=(57 \%)$; IR $\left(\mathrm{KBr}, \mathrm{cm}^{-1}\right): 3428,2926,1755,1611$, $1587,1493,1464,1377,1280,1279,1106,761 ;{ }^{1} \mathrm{H}-\mathrm{NMR}(500 \mathrm{MHz}$, DMSO-d6) : $\delta=4.21\left(\mathrm{~s}, 2 \mathrm{H}, \mathrm{CH}_{2}\right.$-thiazolidinedione), $\delta=4.95(\mathrm{~s}, 2 \mathrm{H}$, $\left.\mathrm{CNOH}-\mathrm{CH}_{2}\right), \delta=7.40(\mathrm{t}, 1 \mathrm{H}, \mathrm{H}-6$ coumarin, $\mathrm{J}=7.62 \mathrm{~Hz}), \delta=7.56(\mathrm{~d}$, $1 \mathrm{H}, \mathrm{H}-8$ coumarin, $\mathrm{J}=7.34 \mathrm{~Hz}), \delta=7.66(\mathrm{dt}, 1 \mathrm{H}, \mathrm{H}-7$ coumarin, $\mathrm{J}=7.33$ and $1.26 \mathrm{~Hz}), \delta=7.77(\mathrm{~d}, 1 \mathrm{H}, \mathrm{H}-5$ coumarin, $\mathrm{J}=7.69 \mathrm{~Hz}), \delta=8.14(\mathrm{~s}$, $1 \mathrm{H}, \mathrm{H}-4$ coumarin $), \delta=11.26\left(\mathrm{~s}, 1 \mathrm{H}\right.$, oxime) $\mathrm{ppm} ;{ }^{13} \mathrm{C}-\mathrm{NMR}(300 \mathrm{MHz}$,
DMSO-d6): $\delta=40.3,57.3,121.6,122.3,127.9,130.8,132.2,133.8,141.6$,

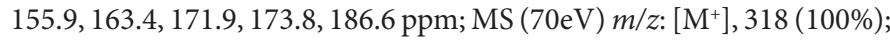
Anal. Calcd for $\mathrm{C}_{14} \mathrm{H}_{10} \mathrm{~N}_{2} \mathrm{O}_{5} \mathrm{~S} 318.0310$, Found 318.0304.

3-(2-(6-bromo-2-oxo-2H-chromen-3-yl)-2-(hydroxyimino) ethyl)thiazolidine-2,4-dione ( $\left.7 \mathrm{~b}, \mathrm{C}_{14} \mathrm{H}_{9} \mathrm{BrN}_{2} \mathrm{O}_{5} \mathrm{~S}\right)$ : Brown powder; M.p: $(177-179)^{\circ} \mathrm{C}$, yield $=(58 \%)$; IR $\left(\mathrm{KBr}, \mathrm{cm}^{-1}\right): 3352,2929,1760,1609$, 1592, 1491, 1455, 1371, 1294, 1205, 1118, 767; ${ }^{1} \mathrm{H}-\mathrm{NMR}(500 \mathrm{MHz}$, DMSO-d6) : $\delta=4.15\left(\mathrm{~s}, 2 \mathrm{H}, \mathrm{CH}_{2}\right.$-thiazolidinedione), $\delta=4.93(\mathrm{~s}, 2 \mathrm{H}$, CNOH-CH $\left.{ }_{2}\right), \delta=7.27-7.43(\mathrm{~m}, 2 \mathrm{H}, \mathrm{H}-7$ and $\mathrm{H}-8$ coumarin), $\delta=7.68(\mathrm{~d}$, $1 \mathrm{H}, \mathrm{H}-5$ coumarin, $\mathrm{J}=8.74 \mathrm{~Hz}), \delta=8.07(\mathrm{~s}, 1 \mathrm{H}, \mathrm{H}-4$ coumarin), $\delta=11.28$ (s, $1 \mathrm{H}$, oxime) ppm; ${ }^{13} \mathrm{C}-\mathrm{NMR}(300 \mathrm{MHz}, \mathrm{DMSO}-\mathrm{d} 6): \delta=40.3,55.2$, $120.3,122.8,126.8,133.4,134.7,136.5,140.8,154.1,164.2,168.3,173.5$,

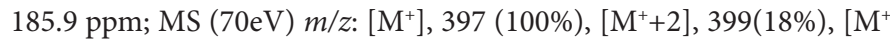
+4], 401 (2.5\%); Anal. Calcd for $\mathrm{C}_{14} \mathrm{H}_{9}^{79} \mathrm{BrN}_{2} \mathrm{O}_{5} \mathrm{~S}$ 397.2007, Found 397.2001 .

3-(2-(hydroxyimino)-2-(8-methoxy-2-oxo-2H-chromen-3-yl) ethyl)thiazolidine-2,4-dione $\left(7 \mathrm{c}, \quad \mathrm{C}_{15} \mathrm{H}_{12} \mathrm{~N}_{2} \mathrm{O}_{6} \mathrm{~S}\right)$ : Brown powder; M.p:(153-155) ${ }^{\circ} \mathrm{C}$, yield $=(59 \%)$; IR $\left(\mathrm{KBr}, \mathrm{cm}^{-1}\right): 3435,2932,1750,1620$, 1595, 1488, 1462, 1383, 1288, 1209, 1100, 781; ${ }^{1} \mathrm{H}-\mathrm{NMR}(500 \mathrm{MHz}$, DMSO-d6) : $\delta=4.19\left(\mathrm{~s}, 2 \mathrm{H}, \mathrm{CH}_{2}\right.$-thiazolidinedione), $\delta=4.05(\mathrm{~s}, 3 \mathrm{H}$, O- $\mathrm{CH}_{3}$ coumarin), $\delta=4.90\left(\mathrm{~s}, 2 \mathrm{H}, \mathrm{CNOH}-\mathrm{CH}_{2}\right), \delta=7.48(\mathrm{dt}, 1 \mathrm{H}, \mathrm{H}-6$ coumarin, $\mathrm{J}=7.84$ and $0.81 \mathrm{~Hz}), \delta=7.75(\mathrm{dt}, 1 \mathrm{H}, \mathrm{H}-7$ coumarin, $\mathrm{J}=8.71$ and $1.58 \mathrm{~Hz}), \delta=7.91(\mathrm{dd}, 1 \mathrm{H}, \mathrm{H}-5$ coumarin, $\mathrm{J}=7.69$ and $1.36 \mathrm{~Hz}$ ), $\delta=8.25(\mathrm{~s}, 1 \mathrm{H}, \mathrm{H}-4$ coumarin $), \delta=11.32\left(\mathrm{~s}, 1 \mathrm{H}\right.$, oxime) $\mathrm{ppm} ;{ }^{13} \mathrm{C}-\mathrm{NMR}$ (300 MHz, DMSO-d6): $\delta=39.5,54.1,58.8,121.6,124.6,127.9,132.6$, $136.3,139.4,143.6,152.6,164.2,171.8,174.3,185.1$ ppm;MS $(70 \mathrm{eV})$ $\mathrm{m} / z$ : $\left[\mathrm{M}^{+}\right], 348$ (100\%); Anal. Calcd for $\mathrm{C}_{15} \mathrm{H}_{12} \mathrm{~N}_{2} \mathrm{O}_{6} \mathrm{~S} 348.3306$, Found 348.3312 .

3-(2-(methoxyimino)-2-(2-oxo-2H-chromen-3-yl)ethyl) thiazolidine-2,4-dione (8a, $\mathrm{C}_{15} \mathbf{H}_{12} \mathbf{N}_{2} \mathbf{O}_{5}$ S): Brown powder; M.p:(157$159)^{\circ} \mathrm{C}$, yield $=(58 \%) ; \operatorname{IR~}\left(\mathrm{KBr}, \mathrm{cm}^{-1}\right): 3425,2934,1757,1615,1595,1488$, 1468, 1382, 1278, 1221, 1114, 763; ${ }^{1} \mathrm{H}-\mathrm{NMR}$ (500 MHz, DMSO-d6): $\delta=4.08$ (s, $3 \mathrm{H}, \mathrm{O}-\mathrm{CH}_{3}$ oxime), $\delta=4.17$ (s, $2 \mathrm{H}, \mathrm{CH}_{2}$-thiazolidinedione), $\delta=4.87\left(\mathrm{~s}, 2 \mathrm{H}, \mathrm{C}-\mathrm{CH}_{2}-\mathrm{N}\right), \delta=7.34(\mathrm{t}, 1 \mathrm{H}, \mathrm{H}-6$ coumarin, $\mathrm{J}=7.52 \mathrm{~Hz})$, $\delta=7.39(\mathrm{~d}, 1 \mathrm{H}, \mathrm{H}-8$ coumarin, $\mathrm{J}=8.62 \mathrm{~Hz}), \delta=7.56-7.62(\mathrm{~m}, 2 \mathrm{H}, \mathrm{H}-5$ and $\mathrm{H}-7$ coumarin), 8.16 (s, $1 \mathrm{H}, \mathrm{H}-4$ coumarin) ppm; ${ }^{13} \mathrm{C}-\mathrm{NMR}(300 \mathrm{MHz}$, DMSO-d6): $\delta=39.8,57.1,63.9,120.9,123.4,126.5,130.1,133.6,134.2$, $142.3,154.8,164.2,172.1,173.6,185.3$ ppm; MS $(70 \mathrm{eV}) \mathrm{m} / \mathrm{z}:\left[\mathrm{M}^{+}\right], 332$ (100\%); Anal. Calcd for $\mathrm{C}_{15} \mathrm{H}_{12} \mathrm{~N}_{2} \mathrm{O}_{5} \mathrm{~S} 332.3312$, Found 332.3303.

3-(2-(6-bromo-2-oxo-2H-chromen-3-yl)-2-(methoxyimino) ethyl)thiazolidine-2,4-dione $\left(8 \mathrm{~b}, \mathrm{C}_{15} \mathrm{H}_{11} \mathrm{BrN}_{2} \mathrm{O}_{5} \mathrm{~S}\right)$ : Brown powder; M.p: $(178-180)^{\circ} \mathrm{C}$, yield $=(60 \%)$; IR $\left(\mathrm{KBr}, \mathrm{cm}^{-1}\right)$ : 3345, 2923, 1751, $1616,1592,1495,1462,1379,1288,1265,1110,755 ;{ }^{1} \mathrm{H}-\mathrm{NMR}(500$ $\mathrm{MHz}, \mathrm{DMSO}-\mathrm{d} 6): \delta=4.09$ (s, $3 \mathrm{H}, \mathrm{O}-\mathrm{CH}_{3}$ oxime), $\delta=4.20\left(\mathrm{~s}, 2 \mathrm{H}_{1} \mathrm{CH}_{2}\right.$ thiazolidinedione), $\delta=4.88\left(\mathrm{~s}, 2 \mathrm{H}, \mathrm{C}-\mathrm{CH}_{2}-\mathrm{N}\right), \delta=7.01-7.55(\mathrm{~m}, 2 \mathrm{H}, \mathrm{H}-7$, $\mathrm{H}-8$ coumarin), $\delta=7.75(\mathrm{~d}, 1 \mathrm{H}, \mathrm{H}-5$ coumarin, $\mathrm{J}=8.76 \mathrm{~Hz}) \delta=8.07(\mathrm{~s}, 1 \mathrm{H}$, $\mathrm{H}-4$ coumarin) ppm; ${ }^{13} \mathrm{C}-\mathrm{NMR}(300 \mathrm{MHz}$, DMSO-d6): $\delta=41.4,57.6$, $64.3,120.9,123.2,127.1,133.4,134.7,135.9,141.2,155.6,163.6,167.6$,

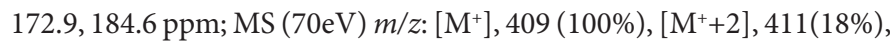
$\left[\mathrm{M}^{+}+4\right], 413$ (2.5\%); Anal. Calcd for $\mathrm{C}_{15} \mathrm{H}_{11}{ }^{79} \mathrm{BrN}_{2} \mathrm{O}_{5} \mathrm{~S} 411.2272$, Found 411.2265 .

3-(2-(8-methoxy-2-oxo-2H-chromen-3-yl)-2-(methoxyimino) ethyl)thiazolidine-2,4-dione (8c, $\left.\mathrm{C}_{16} \mathrm{H}_{14} \mathrm{~N}_{2} \mathrm{O}_{6} \mathrm{~S}\right)$ : Brown powder; M.p: $(162-164)^{\circ} \mathrm{C}$, yield $=(62 \%)$; IR $\left(\mathrm{KBr}, \mathrm{cm}^{-1}\right): 3321,2933,1758,1614$, 1586, 1489, 1452, 1380, 1289, 1206, 1099, 758; ${ }^{1} \mathrm{H}-\mathrm{NMR}(500 \mathrm{MHz}$, DMSO-d6): $\delta=4.03$ (s, $3 \mathrm{H}, \mathrm{O}-\mathrm{CH}_{3}$ coumarin), $\delta=4.12$ (s, $3 \mathrm{H}, \mathrm{O}-\mathrm{CH}_{3}$ oxime), $\delta=4.21$ (s, $2 \mathrm{H}, \mathrm{CH}_{2}$-thiazolidinedione), $\delta=4.92(\mathrm{~s}, 2 \mathrm{H}, 2 \mathrm{H}$, C- $\left.\mathrm{CH}_{2}-\mathrm{N}\right), \delta=7.45(\mathrm{t}, 1 \mathrm{H}, \mathrm{H}-6$ coumarin, J=7.45 Hz), $\delta=7.52-7.66(\mathrm{~m}$, 
Citation: Valadbeigi E, Ghodsi S (2017) Synthesis and Characterization of Some New Thiazolidinedione Derivatives Containing a Coumarin Moiety for their Antibacterial and Antifungal Activities. Med Chem (Los Angeles) 7: 178-185. doi: 10.4172/2161-0444.1000453

$2 \mathrm{H}, \mathrm{H}-5, \mathrm{H}-7$ coumarin), $\delta=8.05$ ( $\mathrm{s}, 1 \mathrm{H}, \mathrm{H}-4$ coumarin) $\mathrm{ppm} ;{ }^{13} \mathrm{C}-\mathrm{NMR}$ (300 MHz, DMSO-d6): $\delta=39.9,55.6,57.9,64.1,122.9,125.1,128.3$, $133.1,136.6,138.3,145.9,151.8,163.8,169.6,171.9,184.3$ ppm; MS $(70 \mathrm{eV}) \mathrm{m} / \mathrm{z}:\left[\mathrm{M}^{+}\right], 362(100 \%) ;$ Anal. Calcd for $\mathrm{C}_{16} \mathrm{H}_{14} \mathrm{~N}_{2} \mathrm{O}_{6} \mathrm{~S} 362.3572$, Found 362.3563 .

3-(2-(benzyloxyimino)-2-(2-oxo-2H-chromen-3-yl)ethyl) thiazolidine-2,4-dione $\left(9 \mathrm{a}, \mathrm{C}_{21} \mathrm{H}_{16} \mathrm{~N}_{2} \mathrm{O}_{5} \mathrm{~S}\right)$ : Brown powder; M.p: (183$185)^{\circ} \mathrm{C}$, yield $=(56 \%)$; IR $\left(\mathrm{KBr}, \mathrm{cm}^{-1}\right): 3425,2920,1759,1619,1586$ $1502,1455,1384,1279,1204,1108,1030,761 ;{ }^{1} \mathrm{H}-\mathrm{NMR}(500 \mathrm{MHz}$, DMSO-d6) : $\delta=3.99\left(\mathrm{~s}, 2 \mathrm{H}, \mathrm{CH}_{2}\right.$-thiazolidinedione), $\delta=4.87(\mathrm{~s}, 2 \mathrm{H}$, $\mathrm{C}-\mathrm{CH}_{2}-\mathrm{N}$ ), $\delta=5.30\left(\mathrm{~s}, 2 \mathrm{H}, \mathrm{O}-\mathrm{CH}_{2}-\mathrm{Ph}\right), \delta=7.33-7.57(\mathrm{~m}, 7 \mathrm{H}, \mathrm{H}-6, \mathrm{H}-8$ coumarin and phenyl), 7.61-7.77 (m, 2H, H-5 and H-7 coumarin), $\delta=8.05$ (s, $1 \mathrm{H}, \mathrm{H}-4$ coumarin) ppm; ${ }^{13} \mathrm{C}-\mathrm{NMR}(300 \mathrm{MHz}, \mathrm{DMSO}-\mathrm{d} 6)$ : $\delta=40.1,56.9,80.8,122.9,123.4,125.7,127.8,129.1(2 \mathrm{C}), 130.8,131.2$ (2C), 132.8, 134.5, 139.6, 142.3, 154.8, 162.9,171.1, 173.6, $184.8 \mathrm{ppm}$; MS $(70 \mathrm{eV}) \mathrm{m} / z$ : $\left[\mathrm{M}^{+}\right], 408(100 \%)$; Anal. Calcd for $\mathrm{C}_{21} \mathrm{H}_{16} \mathrm{~N}_{2} \mathrm{O}_{5} \mathrm{~S}$ 408.4271, Found 408.4265.

3-(2-(benzyloxyimino)-2-(6-bromo-2-oxo-2H-chromen-3yl) ethyl)thiazolidine-2,4-dione $\left(9 \mathrm{~b}, \mathrm{C}_{21} \mathrm{H}_{15} \mathrm{BrN}_{2} \mathrm{O}_{5} \mathrm{~S}\right)$ : Brown powder; M.p: $(190-192)^{\circ} \mathrm{C}$, yield $=(55 \%) ; \operatorname{IR}\left(\mathrm{KBr}, \mathrm{cm}^{-1}\right): 3345,2931,1751,1621$, 1584, 1498, 1460, 1381, 1279, 1206, 1096, 1036, 751; ${ }^{1} \mathrm{H}-\mathrm{NMR}(500$ $\mathrm{MHz}, \mathrm{DMSO}-\mathrm{d} 6): \delta=4.18\left(\mathrm{~s}, 2 \mathrm{H}, \mathrm{CH}_{2}\right.$-thiazolidinedione) $\delta=5.39(\mathrm{~s}$, $\left.2 \mathrm{H}, \mathrm{O}-\mathrm{CH}_{2}-\mathrm{Ph}\right), \delta=4.88\left(\mathrm{~s}, 2 \mathrm{H}, \mathrm{C}-\mathrm{CH}_{2}-\mathrm{N}\right), \delta=5.24\left(\mathrm{~s}, 2 \mathrm{H}, \mathrm{O}-\mathrm{CH}_{2}-\mathrm{Ph}\right)$, $\delta=7.01-7.55(\mathrm{~m}, 7 \mathrm{H}, \mathrm{H}-7, \mathrm{H}-8$ coumarin and phenyl), $\delta=7.72(\mathrm{~d}, 1 \mathrm{H}, \mathrm{H}-5$ coumarin, $\mathrm{J}=8.82 \mathrm{~Hz}), \delta=8.07(\mathrm{~s}, 1 \mathrm{H}, \mathrm{H}-4$ coumarin $) \mathrm{ppm} ;{ }^{13} \mathrm{C}-\mathrm{NMR}$ (300 MHz, DMSO-d6): $\delta=40.1,56.8,63.3,79.8,121.6,123.2,127.1$, 129.6 (2C), 130.1, 131.9 (2C), 133.1, 135.1, 136.3, 140.9, 154.9, 164.2,

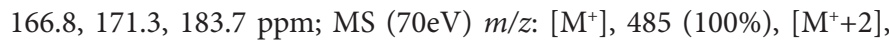
487(18\%), $\left[\mathrm{M}^{+}+4\right], 489$ (2.5\%); Anal. Calcd for $\mathrm{C}_{21} \mathrm{H}_{15}{ }^{79} \mathrm{BrN}_{2} \mathrm{O}_{5} \mathrm{~S}$ 487.3232, Found 487.3224.

3-(2-(benzyloxyimino)-2-(8-methoxy-2-oxo-2H-chromen3yl) ethyl)thiazolidine-2,4-dione $\left(9 \mathrm{c}, \quad \mathrm{C}_{22} \mathrm{H}_{18} \mathrm{~N}_{2} \mathrm{O}_{6} \mathrm{~S}\right)$ : Brown powder;
M.p: $(186-188)^{\circ} \mathrm{C}$, yield $=(54 \%)$; IR $\left(\mathrm{KBr}, \mathrm{cm}^{-1}\right): 3311,2922,1754$, 1600, 1591, 1492, 1467, 1369, 1286, 1216, 1116, 1026, 758; ${ }^{1} \mathrm{H}-\mathrm{NMR}$ (500 MHz, DMSO-d6): $\delta=4.02\left(\mathrm{~s}, 3 \mathrm{H}, \mathrm{O}-\mathrm{CH}_{3}\right.$ coumarin), $\delta=4.21(\mathrm{~s}$, $2 \mathrm{H}, \mathrm{CH}_{2}$-thiazolidinedione), $\delta=4.92\left(\mathrm{~s}, 2 \mathrm{H}, \mathrm{C}-\mathrm{CH}_{2}-\mathrm{N}\right), \delta=5.27(\mathrm{~s}, 2 \mathrm{H}$, $\left.\mathrm{O}-\mathrm{CH}_{2}-\mathrm{Ph}\right), \delta=7.31-7.66(\mathrm{~m}, 7 \mathrm{H}, \mathrm{H}-6, \mathrm{H}-7$ coumarin and phenyl), $\delta=7.84(\mathrm{~d}, 1 \mathrm{H}, \mathrm{H} 5$-coumarin, $\mathrm{J}=7.74 \mathrm{~Hz}), \delta=8.05$ (s, $1 \mathrm{H}, \mathrm{H}-4$ coumarin) ppm; ${ }^{13} \mathrm{C}-\mathrm{NMR}$ (300 MHz, DMSO-d6): $\delta=40.3,54.2,57.3,63.8,79.6$, 122.1, 124.8, 127.3, 128.9 (2C), 130.6, 132.1 (2C), 134.6, 135.8, 138.6 $143.8,152.4,164.1,168.9,172.1,183.5 \mathrm{ppm}$; MS $(70 \mathrm{eV}) \mathrm{m} / \mathrm{z}:\left[\mathrm{M}^{+}\right], 438$ (100\%); Anal. Calcd for $\mathrm{C}_{22} \mathrm{H}_{18} \mathrm{~N}_{2} \mathrm{O}_{6} \mathrm{~S} 438.4531$, Found 438.4523 .

\section{Antimicrobial and antifungal assay}

The antimicrobial activity was assayed by cup-plate agar diffusion method [31,32] by measuring inhibition zones in $\mathrm{mm}$. In vitro antimicrobial activity of all synthesized compounds and standard drugs have been evaluated against two strains of bacteria which include grampositive bacteria such as, Bacillus subtilis PTCC 1207 and gram-negative bacteria such as Escherichia coli PTCC 1047 and fungus Candida kefyr ATCC 38296. The antibacterial and antifungal activity was compared with standard drugs. The purified products were screened for their antibacterial activity by using cup-plate agar diffusion method. The nutrient agar broth prepared by the usual method, was inoculated aseptically with $0.5 \mathrm{ml}$ of $24 \mathrm{~h}$ old subculture of, Bacillus subtilis PTCC 1047, and Escherichia coli PTCC 1047 in separate conical flasks at 40$50^{\circ} \mathrm{C}$ and mixed well by gently shaking. About $25 \mathrm{ml}$ of the contents of the flask was poured and evenly spread in a petri dish $(90 \mathrm{~mm}$ in diameter) and allowed to set for $2 \mathrm{~h}$. The cups (10 $\mathrm{mm}$ in diameter) were formed by the help of borer in agar medium and filled with $0.4 \mathrm{ml}$ $(400 \mu \mathrm{g} / \mathrm{ml})$ solution of sample in DMSO.

The plates were incubated at $37^{\circ} \mathrm{C}$ for $24 \mathrm{~h}$ and the control was also maintained with $0.4 \mathrm{ml}$ of DMSO in a similar manner and the zones of inhibition of the bacterial growth were measured in millimeter and recorded in Table 2 and Figure 2. Candida kefyr ATCC 38296 was<smiles>[X]c1ccc2oc(=O)c(C([Y])CN3C(=O)CSC3=O)cc2c1</smiles>

\begin{tabular}{|c|c|c|c|c|c|}
\hline \multirow[t]{3}{*}{ Compound } & \multirow[t]{3}{*}{$\mathbf{x}$} & \multirow[t]{3}{*}{$\mathbf{Y}$} & \multicolumn{3}{|c|}{ Diameter of the zone of the inhibition $(\mathrm{mm})$} \\
\hline & & & Gram-positive organism & Gram-negative organism & Fungus \\
\hline & & & Bacillus subtilis PTCC 1207 & Escherichia coli PTCC 1047 & Candida kefyr ATCC 38296 \\
\hline $6 a$ & $\mathrm{H}$ & 0 & 15 & 16 & 7 \\
\hline $6 \mathrm{~b}$ & $6-\mathrm{Br}$ & 0 & 17 & 17 & 8 \\
\hline $6 c$ & $8-\mathrm{OCH}_{3}$ & 0 & 16 & 19 & 7 \\
\hline $7 a$ & $\mathrm{H}$ & $\mathrm{NOH}$ & 19 & 20 & 9 \\
\hline $7 \mathrm{~b}$ & $6-\mathrm{Br}$ & $\mathrm{NOH}$ & 17 & 16 & 8 \\
\hline $7 \mathrm{c}$ & $8-\mathrm{OCH}_{3}$ & $\mathrm{NOH}$ & 20 & 15 & 8 \\
\hline $8 a$ & $\mathrm{H}$ & $\mathrm{NOCH}_{3}$ & 25 & 21 & 9 \\
\hline $8 b$ & 6-Br & $\mathrm{NOCH}_{3}$ & 24 & 20 & 9 \\
\hline $8 \mathrm{c}$ & $8-\mathrm{OCH}_{3}$ & $\mathrm{NOCH}_{3}$ & 26 & 22 & 8 \\
\hline $9 a$ & $\mathrm{H}$ & NOBn & 22 & 19 & 9 \\
\hline $9 b$ & $6-\mathrm{Br}$ & NOBn & 23 & 21 & 8 \\
\hline $9 \mathrm{c}$ & $8-\mathrm{OCH}_{3}$ & NOBn & 21 & 19 & 8 \\
\hline Ciprofloxacin & & & 23 & 26 & \\
\hline Ampicillin & & & 15 & 18 & - \\
\hline Gentamicin & & & 21 & 19 & - \\
\hline Nistatin & & & - & - & 12 \\
\hline
\end{tabular}

Table 2: In vitro antibacterial and antifungal activities of compounds $6 \mathrm{a}-9 \mathrm{c}$. 
Citation: Valadbeigi E, Ghodsi S (2017) Synthesis and Characterization of Some New Thiazolidinedione Derivatives Containing a Coumarin Moiety for their Antibacterial and Antifungal Activities. Med Chem (Los Angeles) 7: 178-185. doi: 10.4172/2161-0444.1000453

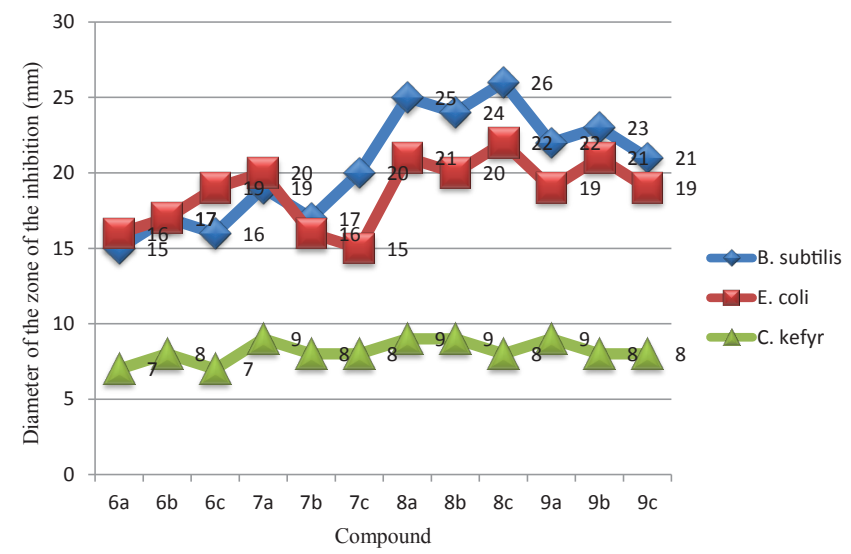

Figure 2: In-vitro antibacterial and antifungal activities of compounds 6a-9c.

employed for testing antifungal activity by cup-plate agar diffusion method. The culture was maintained on Sub rouse dextrose agar slants. Sterilized Sub rouse dextrose agar medium was inoculated with $72 \mathrm{~h}$ old $0.5 \mathrm{ml}$ suspension of fungal spores in a separate flask. About $25 \mathrm{ml}$ of the inoculated medium was evenly spread on a sterilized petri dish and allowed to set for $2 \mathrm{~h}$. The cups (10 $\mathrm{mm}$ in diameter) were punched in a petri dish and loaded with $0.4 \mathrm{ml}(400 \mu \mathrm{g} / \mathrm{ml})$ of solution of sample in DMSO. The plates were incubated at $30^{\circ} \mathrm{C}$ for $48 \mathrm{~h}$. After the completion of incubation period, the zones of inhibition of growth in the form of diameter in $\mathrm{mm}$ were measured. Along with the test solution in each petri dish one cup was filled up with solvent which acts as a control. The zones of inhibition are recorded in Table 2 and Figure 2.

\section{Results and Discussion}

In this study the structure of the synthesized compounds was elucidated by means of IR, ${ }^{1} \mathrm{H}-\mathrm{NMR},{ }^{13} \mathrm{C}-\mathrm{NMR}$ and Mass. All the compounds were evaluated for antibacterial and antifungal activities by cup-plate method. The antimicrobial activity of tested compounds against different strains of bacteria and fungus is shown in Table 2 and Figure 2 . The newly synthesized compounds $6 a-9 c$ were evaluated for their in-vitro antibacterial activity against Bacillus subtilis PTCC 1207, Escherichia coli PTCC 1047 and Candida kefyr ATCC 38296 using conventional by cup-plate agar diffusion method [31,32]. The zone of growth inhibition values were determined by comparison to standard drugs. The zones of growth inhibition obtained for compounds $6 a-9 c$ are presented in Table 2 and Figure 2. The zone of growth inhibition values of the test derivatives indicated that most compounds exhibit good activity against gram-positive and gram-negative bacteria. Antibacterial screening of compounds $6 \mathrm{a}-9 \mathrm{c}$ against gram-positive and gram-negative bacteria reveals that compounds $8 \mathrm{a}, 8 \mathrm{~b}$ and $8 \mathrm{c}$ exhibit the most potent in-vitro antibacterial activity. All compounds show improvement of activity against gram-negative bacteria in comparison to standard drugs. Generally, in both gram-positive and gram-negative bacteria, better results are obtained with $2-\mathrm{NOCH}_{3}$ on the ethyl spacer of coumarin. In conclusion, some of the new thiazolidinedione derivatives $6 \mathrm{a}-9 \mathrm{c}$ containing a carbonyl related functional groups (ketone, oxime, O-methyloxime, and O-benzyloxime) on the ethyl spacer showed considerable antibacterial activity and ethyl spacer functionality produced relatively major changes in terms of activity. In general, the results of antibacterial evaluation of the test compounds in comparison with the reference drugs indicated that compounds $8 \mathrm{a}, 8 \mathrm{~b}$ and $8 \mathrm{c}$ showed comparable or more potent antibacterial activity with respect to the reference drugs against all tested species. The antifungal data reveals that all compounds have shown weak antifungal activity as compared to Nistatin.

\section{Acknowledgements}

The authors of the present paper acknowledge Tabriz University for the helpful support of the work.

\section{References}

1. Fylaktakidou KC, Hadjipavlou-Litina DJ, Litinas KE, Nikolaides DN (2004) Natural and synthetic coumarin derivatives with anti-inflammatory/antioxidant activities. Curr Pharm Des 10: 3813-3818.

2. Mladenova R, Ignatova M, Manolova N, Petrova T (2002) Preparation, characterization and biological activity of Schiff base compounds derived from 8-hydroxyquinoline-2 carboxaldehyde and Jeffamines ED. Eur Polym J 38 989-999.

3. Walsh OM, Meegan MJ, Prendergast RM, Nakib TA (1996) Synthesis of 3-acetoxyazetidin-2ones and 3-hydroxyazetidin-2-ones with antifugal and antifungal and antibacterial activity. Eur J Med. Chem 31: 989-1000.

4. Singh K, Barwa MS, Tyagi P (2006) Synthesis, characterization and biological studies of $\mathrm{Co}(\mathrm{II}), \mathrm{Ni}(\mathrm{II}), \mathrm{Cu}(\mathrm{II})$ and $\mathrm{Zn}(\mathrm{II})$ complexes with bidentate Schiff bases derived by heterocyclic ketone. Eur J Med Chem 41: 147-153.

5. Ahluwalia VK, Anand S, Goyal M, Neghipur GA (1983) Synthesis of $\mathrm{N}$-benzylidene derivatives of 7-hydroxy-4-methyl/phenyl coumarin as potenial fungicides and bactericides. Bokin Bobai 11: 622-634.

6. Sengupta AK, Sen S, Srivastava V (1989) Synthesis of coumarin derivatives as possible antifungal and antibacterial agents. Chem Soc 66: 710-717.

7. Panneerselvam $P$, Nair RR, Vijayalakshmi G, Subramanian EH, Sridhar SK (2005) Synthesis of Schiff bases of 4-(4-aminophenyl)-morpholine as potential antimicrobial agents. Eur J Med Chem 40: 225-229.

8. Sridhar SK, Saravan M, Ramesh A (2001) Synthesis and antibacterial screening of hydrazones, Schiff and Mannich bases of isatin derivatives. Eur J Med Chem 36: 615-625.

9. Pandeya SN, Sriram D, Nath G (1999) Synthesis, antibacterial, antifungal and antiHIV activities of Schiff and Mannich bases derived from isatin derivatives and $\mathrm{N}$-[4-(4'chlorophenyl)thiazol-2-yl]thiosemicarbazide. Eur E J Pharmacol Sci 9: 25-31.

10. Abu-Hussen AAA, Coord J (2006) Synthesis and spectroscopic studies on ternary bis-Schiff-base complexes having oxygen and/or nitrogen donors. Chem 59: 157-176.

11. Karthikeyan MS, Prasad DJ, Poojary B, Subramanya Bhat K (2006) Synthesis and biological activity of Schiff and Mannich bases bearing 2,4-dichloro5fluorophenyl moiety. Bioorg Med Chem 14: 7482-7489.

12. Sharma BM, Parsania MV, Baxi AJ (2008) Synthesis of some azetidinones wih coumarinyl moiety and their antimicrobial activity. Org Chem 4: 304-310.

13. Husain MI, Shukla MA, Agarwal SK (1979) Search for potent anthelmintics. Part VII. Hydrazones derived from 4-substituted 7-coumarinyloxyacetic acid hydrazides. J Ind Chem Soc 56: 306-311.

14. Thangadurai TD, Gowri M, Natarajan K (2002) Synthesis and characterization of ruthenium(III) complexes containing monobasic bidentate Schiff bases and their biological acivities. Synth React Inorg Met Org Chem 32: 329-343.

15. Pulici M, Quartieri F (2005) Synthesis of 2-Amino-5-alkylidene-thiazol-4-ones. Tetrahedron Lett 46: 2387-2391.

16. Brown FC (1961) 4-Thiazolidinones. Chem Rev 41: 464-469

17. Manojkumar P, Ravi TK, Subbuchettiar G (2009) Synthesis of coumarin heterocyclic derivatives with antioxidant activity and in vitro cytotoxic activity against tumour cells. Acta Pharm 59: 159-170

18. Verma A, Saraf SH (2008) 4-Thiazolidinone - A biologically active scaffold. Eur J Med Chem 43: 897-905.

19. Hall A, Brown SH, Chowdhury A, Giblin GMP, Gibson M (2007) Identification and optimization of novel1,3,4-oxadiazole EP1 receptor antagonists. Bioorg Med Chem Lett 17: 4450-4455.

20. Abdel-Hamid MK, El-Koussi AA, Mahfouz NA, Innocenti NM, Supuran A (2007) 
Citation: Valadbeigi E, Ghodsi S (2017) Synthesis and Characterization of Some New Thiazolidinedione Derivatives Containing a Coumarin Moiety for their Antibacterial and Antifungal Activities. Med Chem (Los Angeles) 7: 178-185. doi: 10.4172/2161-0444.1000453

Design, synthesis, and docking studies of new 1,3,4-thiadiazole-2-thione derivatives with carbonic anhydrase inhibitory activity. Bioorg Med Chem 15: 6975-6984.

21. Amir M, Kumar H, Javed SA (2007) Synthesis and pharmacological evaluation of condensed heterocyclic 6-substituted-1,2,4-triazolo[3,4-b]-1,3,4-thiadiazole derivatives of naproxen. Bioorg Med Chem Lett 17: 4504-4508.

22. Zheng L, Wang XC (2011) Synthesis and biological screening of some new 2,5-disubstitued 1,3,4-oxadiazoles. Int J Pharm Sci 3: 110-114.

23. Amir M, Shahani S (2009) Oxadiazole: A biologically important heterocycle. Indian J Heterocycl Chem 1: 130-138.

24. Hazarika J, Kataky JCS (1998) Synthesis of some novel 1,3,4-oxadiazole and its anti-bacterial and anti-fungal activity. Indian J Heterocycl Chem 7: 83-88.

25. Gao WQ, Li QY, Chen J, Wang ZC, Hua CL (2013) Total synthesis of six 3,4-unsubstituted coumarins. Molecules 18: 15613-15623.

26. Penning-Van Beest FJ, Koerselman J, Herings RM (2008) Risk of major bleeding during concomitant use of antibiotic drugs and coumarin anticoagulants. Haemost 6: 284-290.
27. Liu H, Li Z, Yu L, Zhang Y (2005) Antitumor activity and mechanisms of scoparone 22: 40-46.

28. Liu W, Hua J, Zhou J, Zhang H, Zhu H, et al. (2012) Synthesis and in vitro antitumor activity of novel scopoletin derivatives. Bioorg Med Chem Lett 22 5008-5012.

29. Foroumadi A, Oboudiat M, Emami S, Karimollah A (2006) Synthesis and in vitro antibacterial activity of $\mathrm{N}$-piperazinyl quinolone derivatives with 5-chloro2-thienyl group. Bioorg Med Chem 14: 3421-3429.

30. Foroumadi A, Emami S, Mehni M, Moshafi MH, Shafiee A (2005) Synthesis and antibacterial activity of $\mathrm{N}$-[2-(5-bromothiophen-2-yl)-2-oxoethyl] and $\mathrm{N}-[(2-$ 5 bromothiophen-2-yl)-2-oximinoethyl] derivatives of piperazinyl quinolones. Bioorg Med Chem Lett 15: 4536-4546.

31. Barry AL (1991) Procedure and Theoretical Consideration for testing antimicrobial agents in Agar media. 5th edn. William Wilkins Baltimore.

32. Shah SS, Goswami K (2013) Synthesis, characterization and antimicrobial activity of some novel chalcone Compounds having benzyloxymonochlororesacetophenone moiety. Der Pharma Chemica 5: 75-82. 